\title{
High School Students' Performances on Proof Comprehension Tests
}

\author{
Bahattin İnam ${ }^{(D)}$, Işıkhan Uğurel ${ }^{(D 2}$, Burçak Boz Yaman $\left(\mathbb{D}^{*}\right)^{*}$
}

${ }^{1}$ Şehit Aydın Berber Mesleki ve Teknik Anadolu Lisesi, Çaycuma, Zonguldak, Turkey

${ }^{2}$ Mathematics and Science Education Department, Dokuz Eylül University, İzmir, Turkey

${ }^{3}$ Mathematics and Science Education Department, Muğla Sıtkı Koçman University, Muğla, Turkey

\begin{abstract}
This study is a part of a large scale project in which an action research design is used to teach proof to $11^{\text {th }}$ grade students. This part of the project aims to identify students' comprehension level through five proof comprehension tests developed by the researchers based on the National Geometry Curriculum. Data were analyzed by considering the framework of Yang and Lin's (2008) multilevel model. Results showed none of the students were successful at the most sophisticated level of the proof comprehension tests which requires conducting a proof in various ways or proving different theorems by using the same proof methods. Moreover, the highest proof comprehension was obtained from the level containing knowledge about definition, properties, and meanings of symbols. Achievement and comprehension decreased for components of a proof needing higher level mathematical skills. Based on the study's results, suggestions about teaching proof are provided.
\end{abstract}

\section{ARTICLE HISTORY}

Received: 17 January 2018

Revised: 10 April 2018

Accepted: 13 April 2018

\section{KEYWORDS}

Proof, proving,

Comprehension of proof, Proof comprehension test, High school student, Mathematics education

\section{INTRODUCTION}

A mathematical proof is used to verify a result; inform and convince others; discover a result; and arrange results into a deductive system (Almeida, 2003). It is a concept containing mental processes like identifying mathematical structures and invariants, exploring, proposing assumptions, and organizing logical arguments (Ball, Hoyles, Jahnke, \& Movshovitz-Hadar, 2002). Proof includes not only understanding a concept and the mental processes, but also realizing how and why the concept definition and mental processes work (Tall, 1992). Mathematical proof and proving is central to improving mathematical thinking also advanced mathematical thinking and performing mathematics, comprehending structure and the nature of mathematical knowledge. Moreover, it is important for understanding historical evolvement and type of mathematical objects, the way of developing and sharing them with society and as an individual (Uğurel \& Moral1, 2010). When we think about all these properties, proof and proving is important not only for providing justification for mathematical knowledge, but also

CONTACT: Burçak Boz Yaman $\square$ burcakboz@gmail.com Mathematics and Science Education Department, Muğla Sıtkı Koçman University, Muğla, Turkey

ISSN-e: 2148-7456/(C) IJATE 2018 
for doing and understanding mathematics. Therefore, it is necessary for constructing and developing mathematical knowledge and communicating mathematically (Stylianides, 2007). Learning proof is an important topic for all levels of education in order for mathematics education to be effective; however, research shows students have difficulties conducting and understanding proof. Sar1 (2011) asserted that many researchers focused on existing problems and their elimination. Sar1 (2011, p.19) listed the following problems researched in the literature [Note: citations in the following bullet points are 'as cited by Sar1 (2011)'].

- Perceptions of proof and inadequate understanding of concept of proof, meaning of proof, role of proof, aim of proof, and necessity of proof (Alibert \& Thomas, 1991; Almeida, 2000; Harel \& Sowder, 2007; Knapp, 2005; Knuth \& Elliot, 1997; Martin \& Harel, 1989; Weber, 2006).

- Not knowing how to start a proof (Atwood, 2001; Baker \& Campbell, 2004; Moore, 1994; Selden \& Selden, 2007a).

- Inadequate knowledge about mathematical definitions, role and importance of definition in mathematics, and how to use them (Atwood, 2001; Edwards \& Ward, 2004; Knapp, 2006).

- Insufficient information about a theorem or concept (Dreyfus, 1999; Hart, 1994; Ko \& Knuth, 2009; Moore, 1994; Weber, 2006).

- Even with knowledge of theorem and concept, could not use them properly (Pedemonte, 2007; Selden \& Selden, 2007a; Weber, 2001).

- Deficiencies about logic, and inadequacy of using quantifiers (Atwood, 2001; Baker \& Campbell, 2004; Epp, 2003; Harel \& Sowder, 2007; Selden \& Selden, 2007a).

- Could not reach maturity and proficiency logically; could not follow chain of reasoning (Harel \& Sowder, 2007; Knapp, 2005; Selden \& Selden, 1995; Weber, 2001).

- Inadequately knowing mathematical proof methods and techniques, and not applying them correctly (Antonini \& Mariotti, 2007, 2008; Goetting, 1995; Stylianides et al., 2004, 2007; Thompson, 1996; Wu Yu et al., 2003).

- Inability with mathematical language (differences between daily and mathematical language); make it difficult to understand mathematical language (Baker \& Campbell, 2004; Epp, 2003; Ferrari, 2004; Selden \& Selden, 2007a).

- Inability to write mathematical proof or explain thoughts (Dreyfus, 1999; Dubinsky, 2000; Ko \& Knuth, 2009; Weber \& Alcock, 2009).

One main point of the findings listed above, and also from other studies (Di Martino \& Maracci, 2009; Hemmi, 2008; Remillard, 2010), are the knowledge and skill deficiencies in general mechanism and stages of a proof. This reveals the importance of understanding a mechanism of proof and its components. Consequently, the process of understanding/comprehending a proof and the process dynamics are fundamental to teaching proof.

\subsection{Comprehending Proof}

To evaluate understanding of a proof, students are usually asked to repeat the given proof or apply within a similar theorem (Weber \& Mejia-Ramos, 2011). This evaluation approach makes the form of proof more important than the meaning of proof (Lin \& Yang, 2007), and it depends more on memorizing than comprehending the proof. However, new learning approaches focus on conceptual learning (National Council of Teachers of Mathematics [NCTM], 2000; Ministry of National Mathematics Education [MoNE], 2013). How a proof is comprehended is essential, yet researchers have different ideas about understanding and comprehending a proof. 
One model about how a proof is better comprehended is suggested by Leron (1983), who presented mathematical proofs in a step-by-step, one directional linear style, from hypothesis to conclusion. Leron emphasized the method's appropriateness to hold validity of proof, yet inadequate for communicating mathematical knowledge. He claimed that proofs restructured as short, independent modules emphasizing specific knowledge/ideas are comprehended better, and he introduced the structural model of teaching.

Selden and Selden (1995) stated that before comprehending a proof as a whole, comprehending expression of a proof is more important. Mejia-Ramos (2008) divides reading proof activities into "understanding proof" and "evaluating proof"; illustrating mathematics textbook proof reading activities as an example for understanding proof, and teacher assessment of proof for evaluating proof. Mejia-Ramos (2008) stated that proof reading activities should not only control proof validity, but also focus on understanding the context of that proof. In understanding a proof, Weber and Mejia-Ramos (2011) expressed just knowing the proof steps is inadequate; understanding a proof logically is central to comprehending a proof. Duval (2002) stated three kinds of learning occur when comprehending a proof. First one is learning the meaning of terms, symbols or shapes used in a proof. The second knowledge is inserting expressions in proof steps; deciding which statements are preliminary, definition, or conclusion. Before deciding the required statement of proof, students cannot decide where to start or end. The last knowledge is to be able to explain transition among proof steps.

Stylianides (2007) defined mathematical argument as "Proof is a mathematical argument, a connected sequence of assertions for or against a mathematical claim" (p.291), stating that comprehending an argument as a proof requires a four-way evaluation:

Basic: Comprehending statements (like definition, axiom) that constitute a proof and understanding the roles in a proof.

Formulation: Comprehending proof development and what generalization could be logically conducted in proof steps.

Presentation: Comprehending language used in expressing a proof. A comprehended proof can be expressed in a student's own words.

Social dimension: Satisfying the truthfulness of a proof for each individual. Each presented proof should be appropriate for a group's academic level, with each group member convinced of the proof's truthfulness.

Another holistic approach on proof comprehension is presented by Yang and Lin (2008) and Yang, Lin, and Wang (2008). Lin and Yang (2007) suggest a model for reading comprehension of geometry proof, including learning to comprehend a proof, comprehending levels generated in such learning, and different question types to identify levels of comprehension. They explain that "reading is not only recognition of words and recall of their meaning, but also an active and constructive process between readers, media and contents" (Yang et al., 2008, p.80). However, comprehending a proof is explained as "reading comprehension of proofs means understanding proofs from the essential elements of knowing how a proof operates and why a proof is right, in addition to knowing what a proof can prove" (Yang \& Lin, 2008, p.60). According to this model, students should first recognize premises, then use premises to construct a connection between results, and finally combine premises and results to construct new comprehension. Based on this theoretical structure, four levels identify how a proof is read by comprehending. Among all the other proof comprehending models Yang and Lin (2008) give a well-designed and multi-dimensional structure which is easy to evaluate and follow students' proving processes. The details of the model will be presented below. 


\subsection{Model for Reading Proof by Comprehending}

Yang and Lin (2008) constructed a four-level model (Figure 1). The first level (Surface) is to grasp the meaning of mathematical terms, symbols, or figures in a proof. The second level (Recognizing Elements (pieces)) defines the logical state of the expressions (obvious or latent), and includes recognition of premises, conclusions. The next level (Chaining Elements (relations)) is comprehending and combining logical arguments in a proof. The final level (Encapsulation) is deciding how to conduct a proof in another situation and internalizing propositions of a proof. They define encapsulation as "a developmental situation without end" (p.71), stating their model for comprehending a proof is aimed at identifying students who reach this last level. In their multidimensional model, Yang and Lin (2008) construct "facets" to organize the necessary learning in switching between the four levels of Figure 2.

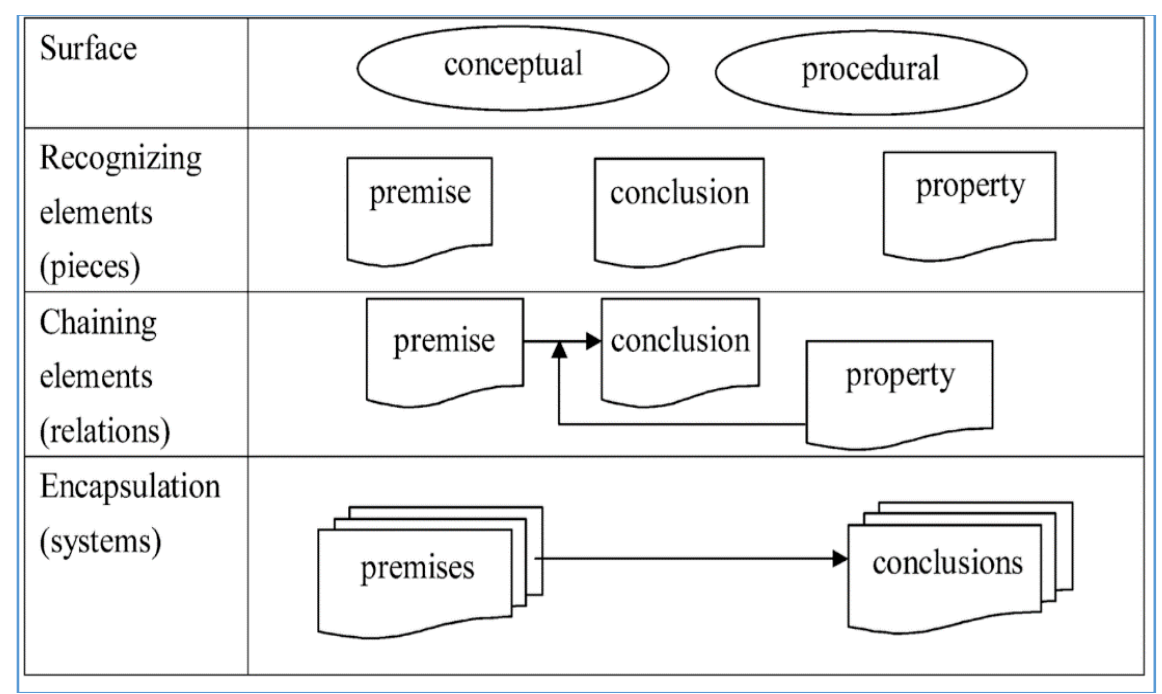

Figure 1. Proof reading comprehension model (Yang \& Lin, 2008, p.63)

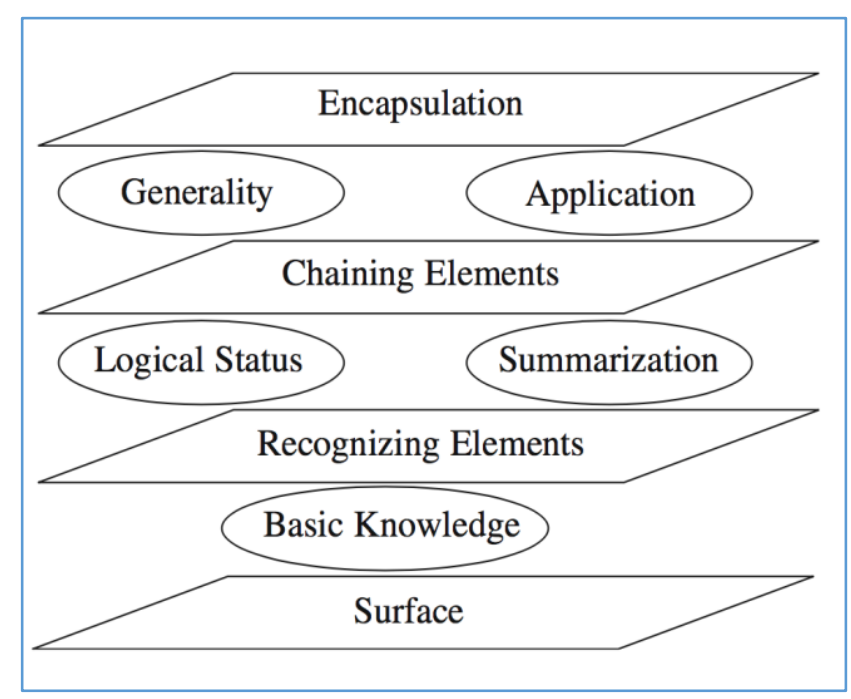

Figure 2. Proof reading comprehension theoretical model (Yang \& Lin, 2008, p.71)

The model explains a five-faceted structured. The facets are pretending as a passage between two levels. A person who hold the knowledge of the related facet can move on the next level. For instance, the first facet "Basic Knowledge" is needed to move up to the Recognizing Elements level. This facet measures understanding of mathematical terms, figures, and symbols 
in premises and proofs. The second facet (Logical Status) and third one (Summarization) are needed to switch from Recognizing Elements to Chaining Elements. Logical Status requires the recognition of arguments as premises, conclusion, or applied properties in a proof. Summarization defines the core or critical idea in a proof. The fourth (Generality) and fifth (Application) facets are necessary to switch from Chaining Elements to Encapsulation. Generality identifies the accuracy of a proposition and understanding what a proof will prove. Application requires the application of proven proposition in another situation. These five facets and four levels construct a model for comprehending a proof.

In the current study, a Proof Comprehending Test (PCT) conducted based on comprehending a proof model is used to identify the degree of students' comprehension of the five facets. Table 1 explains the learning objects used and which learning behavior occurs in the constructed PCT to reveal component-level comprehension of Yang and Lin's (2008) multidimensional model.

Table 1. Structure of reading geometric proof by comprehending (Yang \& Lin, 2008)

\begin{tabular}{|c|c|c|}
\hline Facet & Object of comprehension & Operational definition \\
\hline \multirow{3}{*}{ Basic Knowledge } & \multirow{3}{*}{ Content of premise or conclusion } & $\begin{array}{l}\text { Recognizing the meaning of a } \\
\text { symbol }\end{array}$ \\
\hline & & $\begin{array}{l}\text { Explaining the meaning of a } \\
\text { property }\end{array}$ \\
\hline & & $\begin{array}{l}\text { Recognizing the meaning of a } \\
\text { property }\end{array}$ \\
\hline \multirow{3}{*}{ Logical Status } & Status of premise & $\begin{array}{l}\text { Cognizing a condition applied } \\
\text { directly }\end{array}$ \\
\hline & $\begin{array}{l}\text { Logical relation between premise and } \\
\text { conclusion }\end{array}$ & Judging logical order of statements \\
\hline & $\begin{array}{l}\text { Property applied to derive conclusion } \\
\text { from premise }\end{array}$ & Recognizing which properties apply \\
\hline \multirow[t]{2}{*}{ Summarization } & \multirow[t]{2}{*}{ Multiple arguments and critical ideas } & $\begin{array}{l}\text { Identifying critical procedures, } \\
\text { premises, or conclusions }\end{array}$ \\
\hline & & Identifying critical ideas of a proof \\
\hline \multirow{2}{*}{ Generality } & Proposition or proof & Judging correctness \\
\hline & All arguments and attached figure & Identifying what a proof validates \\
\hline \multirow{2}{*}{ Application } & Application in same premise & Application in same premise \\
\hline & Identifying different premises & Identifying different premises \\
\hline
\end{tabular}

\subsection{Proof Comprehension Tests}

It should be noted that, although many research studies prefer "comprehension test" over "proof comprehension test", PCT was chosen for the current study to narrow down its usability. Houston (1993a, 1993b) was the pioneer whose research studies directly conducted comprehension tests. Houston (1993a) used writing comprehension test in a college mathematics course to develop and evaluate student understanding of reading and writing 
ability for mathematical modelling texts. Houston was inspired by a comprehension test used in an English course with students given a text and asked questions about it. Then he conducted comprehension tests with specific text from a mathematics curriculum. He let students work on the prepared text individually or as a group in order to understand the text, and then applied questions he had prepared to understand their text comprehension.

Conradie and Frith's (2000) long-term research studied comprehension testing at Cape Town University, South Africa, for freshman to senior-year students. The researchers applied similar comprehension tests to Houston (1993a, 1993b), but their tests used proof as a text. The basic properties of Conradie and Frith's (2000) comprehension test study was that theorems were presented with their proofs and students questioned on properties of the proofs. Comprehension test philosophy is that during application, students' understanding can be deeply investigated, and that learning with memorizing is prevented. Conradie and Frith (2000) specified comprehension test advantages as;

- It encourages to understand theorems and proofs rather than memorization.

- A comprehension test gives a far more precise evaluation of a student's understanding at all levels.

- Improves the quality of feedback of both teacher and student.

- According to classical methods it is less frustrating.

- Improves mathematical communication skills.

According to them, comprehension test uses testing to understand; special steps in a proof, structure of a proof, concepts used in proofs, results of the assumptions, and critical perspectives of a proof. On the other hand, Conradie and Frith (2000) list some disadvantages of using PCT;

- Need more time comparing with the traditional methods.

- It may prevent some students' interest in theoretical part of the lesson.

- Students may think they cannot prepare for comprehension tests.

Besides Conradie and Frith (2000), Yang and Lin (2008) developed an instrument for measuring Reading Comprehension of Geometry Proof (RCGP) based on multidimensional model of comprehending a proof with four levels. Whilst Conradie and Frith (2000) do not specify criteria in the context of the questions asked to students, the PCT (we called RCGP as Proof Comprehension Test -PCT) developed by Yang and Lin (2008) has questions matched to each level, and their model is also appropriate for evaluating learning behaviour.

Although PCTs are functional tools for comprehending proofs, there has been limited research to date on the teaching and learning of proofs. The current study is aimed at bridging part of this knowledge gap.

\subsection{Basis for the Study}

Yang and Lin are pioneers who used PCT effectively for understanding/ comprehending proofs by students and led more people to use this tool for teaching proofs. They suggested a four-level model for comprehending proofs in a series of studies (Lin \& Yang, 2007; Yang, 2012; Yang \& Lin, 2008), and produced a proof comprehension test based on these levels. Yang and Lin (2008) used only one PCT (one geometry proof with 16 questions) to conduct their model. They then (Yang, 2012; Yang \& Lin, 2008) developed PCT to investigate the functionality of models and analyze the relationship of students' geometrical knowledge and logical reasoning. They did not specify the tool as a (proof) comprehending test, but when the format of the proof and the related questions are considered, it can be seen as a PCT that has been systematically elaborated and applied to the developed model. 
Roy, Alcock, and Inglis (2010) used Yang and Lin's (2008) proof comprehending tests at the undergraduate level to investigate the effects of presenting proofs in different forms on comprehension. Alcock and Wilkinson (2011) designed an electronic (e-)proof to support mathematical proofs for undergraduates, based on Yang and Lin's (2008) levels of comprehension. Similarly, Mejia-Ramos, Fuller, Weber, Rhoads, and Samkoff (2012) developed another model involving different comprehension levels for undergraduates based on the model developed by Yang and Lin (2008). In a study conducted with middle school preservice teachers, Zazkis and Zazkis (2014) tried to identify how preservice teachers evaluate students' understanding of proof. Preservice teachers were asked to construct probable "proof scenarios", with realistic dialogue between students and teacher based on proof comprehension levels prepared by Mejia-Ramos et al. (2012). In Zazkis and Zazkis' (2014) study, the analysis was conducted based on the third level of the model, "Justification of claims". In Turkey, Yildiz (2006) conducted a proof comprehension test with four preservice mathematics teachers and analyzed their thoughts regarding the test. Another study on proof comprehension test was conducted by İnam \& Ugurel (2016). The researchers investigated difficulties of teachers who conducted a PCT-based secondary school mathematics course, examining teachers' interventions and their effectiveness.

Although the area of proof teaching has been much researched, there are limited studies on the comprehension of proof based on PCT. Most studies have been at college level and based on a single proof comprehension test. Most studies about PCT (e.g., Conradie \& Frith, 2000; Houston, 1993a, 1993b; Yang \& Lin, 2008) are not process-centered, but mostly focus on situational explanation. The purpose of the current study is examining the $11^{\text {th }}$ grade students' proof comprehension levels based on Yang and Lin's (2008) model. The corresponding research question for this current study is, "What is the $11^{\text {th }}$ grade students' performance in proof comprehension tests based on quadrilateral?"

Therefore, the current study will contribute to the literature as a qualitative study with a teaching application, and as an action study applied within a secondary school. We believe that the current research will address a gap in the proof comprehension test literature and aid new research.

\section{METHOD}

This study forms part of a comprehensive qualitative research project. The main project is planned within a qualitative paradigm and constructed as an action research design. According to Koshy (2005), the first action research step is identifying the topic of study, then the group to be studied is identified. The basic concepts/knowledge should be constructed. The tools that help follow the process are clarified and the plan conducted. Once the collected data is examined, the plan is redesigned according to the results. This cycle continues until the aim of the study is reached.

In the main large scale project, PCT-based teaching is conducted in a secondary school classroom for five weeks and the process is evaluated from many perspectives (evaluating teaching process, opinions on PCT, performance on PCT, etc.). The current study, as part of the overall project, investigated the performance of students on 5 PCTs conducted for five weeks.

\subsection{Participants}

The participants were selected based on typical case sampling method, which involves identifying "typical" among a series of cases which helps to introduce a new application or novelty (Yıldırım \& Şimşek, 2013). In this method, "the critical part is selecting average and typical, not extraordinary” (Büyüköztürk, Kılıç-Çakmak, Akgün, Karadeniz, \& Demirel, 2014, p.91). The current study was conducted with 20 students (6 males, 14 females) aged 16 years 
attending 11th grade at a state high school in Zonguldak province, Turkey, and one mathematics teacher (one of the researchers). While selecting the study site, perspectives considered were; convenience of reaching the participants, a school teaching the reformed geometry curriculum, and voluntary student participation. Selection from among the teacher's geometry classes was dependent on heterogeneity of geometry achievement and volunteering. Before conducting the study, the teacher briefed the students about PCT and the research process. No PCT application or investigation was conducted at this stage. Participants had some basic knowledge about proof and proving based on their 10th grade mathematics curriculum, but not proof comprehension testing. Participants' cumulative Grade Point Average (GPA) was 3.79 (out of 5) at 9th grade and 3.71 at 10th grade. All students had selected mostly science and mathematics courses after 9 th grade.

The teacher accompanied the students throughout the study process. He taught mathematics and geometry to the participants since 9th grade and is their classroom teacher, so therefore knowledgeable about the students' academic development. Since the teacher knows each student well, it is perceived that during the PCT process its effect can be easily monitored. The teacher is knowledgeable about PCT, having studied PCT for two years by reviewing the literature, analyzing PCT examples, developing, implementing and evaluating PCT, and hosting a seminar for other teachers. Application sessions were organized based on student school schedules. Students were assured recordings were for academic purposes only, with real names replaced by pseudonyms and gathered data not used for purposes beyond academic aims.

\subsection{Data Gathering Tools (PCT)}

In the big scale study there are five different types of data gathering tools; pre and post free writings of students, teacher-researcher's reflective journals, students' interviews and constructed PCTs. On the other hand, in the current study the constructed PCTs are considered as data gathering tool.

A literature review was conducted while producing the data gathering tools and other proof comprehension tests examined. PCT which consists of all secondary school geometry topics, prepared from examples in the literature and the national mathematics curriculum. The researchers intensely examined 9-12th grade Geometry Curriculum, textbooks, other resources to identify theorems and premises appropriate and functional for PCT. Based on teaching experience, the teacher-researcher selected proof problems according to difficulty level, background information, and classroom applicability in a reasonable timeframe. Eight theorem were initially identified based on these properties. The selected eight theorems were examined by another content specialist for applicability and transferability as a PCT item, and consequently five of the theorems selected. The selected theorems are about "quadrilateral" in the 11th grade Geometry Curriculum of the Ministry of National Education (MoNE, 2010).

There are three process standards are in the related unit, with two selected for the study: "Process standard 2: Prove the theorems about quadrilaterals and conduct applications" (MoNE, 2010, p.32), and "Process standard 3: Calculate the circumstance of quadrilateral and prove theorems about area of quadrilaterals and conduct applications." (MoNE, 2010, p.33). In the curriculum explanation, the learning behaviors mentioned in the process standards, their scope and limits are described. According to this framework, content of the produced PCTs, related process standards and curriculum explanations are as follows;

PCT-1 is prepared for conclusion of "the sum of interior angles of quadrilateral is 360 degrees" (process standard 2) (PCT-1 is given at Appendix).

PCT-2 is prepared for the theorem "the angle produced by two angle bisectors from adjacent two interior angles of a quadrilateral is equal to half of the summation of other two quadrilateral's angles." (process standard 2). 
PCT-3 is prepared for the explanation "In any ABCD quadrilateral, if the diagonals are intersecting perpendicularly then the addition of square of opposite sides are equal to each other." (MoNE, 2010, p.32) (process standard 2).

PCT-4 is prepared for the explanation "Prove that the area of convex quadrilateral region is equal to half of the multiplication of diagonals' length and sine of an angle between diagonals" (MoNE, 2010, p.33) (process standard 3).

PCT-5 is prepared for the explanation "An area of a quadrilateral whose corners are the mid points of sides of a quadrilateral is half of the quadrilateral" (MoNE, 2010, p.32) (process standard 3).

After these stages, the selected five theorems were reconstructed according to PCT format. The draft PCT forms were applied to ten 11th grade students not participating in the study. According to both written answers and informal interviews, the PCT were reviewed again for understandability, difficulty, and practicability. Additionally, three teachers were asked to examine the PCTs. Prior to their examination, the teachers were informed about PCTs, given examples, and the aim of the study and problems explained. Afterwards, based on feedback, ideas, and suggestions, the PCTs were reconstructed to become the original forms. These original forms were then re-examined by the three teachers and the researchers of the current study. Final changes were then applied to form the final version for application.

\subsection{Application of PCT}

Five PCTs were applied to 11th grade students for a period of five weeks in two class hours (40 minutes each). In the first application session students were given a worksheet containing PCT-1. They were briefly informed about PCT before the application. They started to answer questions in a small group, but they had many questions about PCT since this was their first experience attempting to answer such proof questions. In the second class hour, it was realized that the students were experiencing difficulties in answering the questions; therefore, PCT-1 was shown on the projection screen and a classroom discussion held for each question. In the following week, PCT-2 was given to the students as a worksheet, and this time they were tasked with answering questions by themselves. In this session the students pointed out that when they could not answer one of the steps in a question, they were unable to move on to the next. This criticism was taken into consideration and the next PCTs were redesigned accordingly. In PCT-3 the application procedure changed back to being a group study followed by individual study, with restricted time allowed and options given for group discussions. If the students wanted to work as a group they were permitted to discuss the PCT within the group for 10 minutes, after which they had to answers the questions by themselves or continue studying by themselves during the remainder of the class hour. PCT- 4 application was also conducted in the same way, with 10 minute-group-discussion, followed by 30 minutes for individual question answering. In the final application, the questions were answered by individuals during the first class hour and then in the second class hour the teacher/researcher presented another theorem from the textbook. The application was ended with this last PCT.

\subsection{Data Analysis}

A mixed data analysis is used for the current study (Creswell, 2003). As a qualitative analysis part, Yang and Lin's (2008) analysis methods were replicated to analyze the PCT. Each question in the comprehending test is related to facets of Yang and Lin's (2008) model, with learning goals identified for each question. Therefore, students' written answers gathered from tests are first examined and classified through the model.

As a quantitative part of the data analysis process, questions were coded as 0,1 , or 2 according to the degree of reaching the determined learning goals. In Table 2, Evaluation 
Criteria for PCT-1 is given as an example. If the answer fully meets the determined learning goal, it was coded as ' 2 '; with ' 1 ' for partially meeting the determined learning goal; and ' 0 ' for not meeting any of the learning goals. Each comprehension test was examined and graded by the researcher-teacher, and a teacher working at the same school to achieve grading reliability. Afterwards, the teachers compared their grading and a final grading agreed. Finally, random selection of eight PCT coded by the second author and the results were compared for coding reliability.

Table 2. PCT-1 Evaluation Criteria

\begin{tabular}{llcc}
\hline Facet & Learning Goal & Question & Grades \\
\hline \multirow{2}{*}{ Basic Knowledge } & Defining terms in a proof & 1 & $0,1,2$ \\
& Questioning truthiness of properties in a proof & 2 & $0,1,2$ \\
& Explaining applied property & 3 & $0,1,2$ \\
Logical status & Verifying logical orders in a proof & 4 & $0,1,2$ \\
& Verifying logical orders in a proof & 5 & $0,1,2$ \\
\multirow{2}{*}{ Summarization } & Identifying critical step(s) in a proof & 6 & $0,1,2$ \\
& Questioning the truthiness of a proof & 7 & $0,1,2$ \\
Generality & Explaining truthiness of a proof & 8 & $0,1,2$ \\
\multirow{2}{*}{ Application } & Conducting a proof in a different way & 9 & $0,1,2$ \\
& Applying a proof to different situations & 10 & $0,1,2$ \\
\hline
\end{tabular}

Next, the performance percentages for levels of proof comprehension were identified. The highest grades achievable for questions regarding a comprehension facet were determined, and then the grades achieved were used to calculate the percentage. Finally, as with Yang and Lin's (2008) analysis, the calculated performance percentages were evaluated in three groups. Students with performance percentages of $0-33 \%$ from comprehension levels were classified as the 'low group'; with $34-66 \%$ as the 'medium group'; and $67-100 \%$ as the 'high group'.

As an example, Questions 9 and 10 in PCT-1 (Appendix) are designed concerning the Application facet. Student S6 could not answer Question 9 and scored 0, but scored 2 by correctly answering Question 10 (see Figure 3). The highest score achievable from both questions was 4 points. The comprehension level of this student is therefore $50 \%$, with 2 points scored out of 4 . Finally, since the percentage scored is $33-66 \%$, the student is placed in the 'medium group' for the Application facet.

\section{FINDINGS}

\subsection{Analysis Results: PCT-1}

PCT-1 was prepared for 'process standard 2' of quadrilateral unit, taken from the 11th grade geometry curriculum (MoNE, 2010). The theorem is the "sum of interior angles of a quadrilateral is 360 degrees", which is from the explanation part of the related process standard. Students' answers for each questions were graded as 0-1-2 (see Data Analysis section) and performance percentages then calculated. Ten questions were prepared for the proof presented in PCT-1 (see Appendix). Answers to these questions were evaluated according to determined facets. Results are presented in Table 3. 
When Table 3 is examined for Questions 1 and 2 on the Basic Knowledge (F1) facet, regarding symbols and statements of proof, participant performance is medium (approximately $(80+43) / 2=62 \%)$. Performances are at the medium level $(45 \%)$ for three facets; Logical Status (F2) on comprehension of passes among proof steps, Summarization (F3) on comprehension of critical ideas in a proof, and Generality (F4) in which accuracy of proof is questioned.

Table 3. PCT-1 scores and total percentages by facet

\begin{tabular}{lccccccccccccccccccccc} 
PCT-1 & S1 & S2 & S3 & S4 & S5 & S6 & S7 & S8 & S9 & S10 & S1l & S12 & S13 & S14 & S15 & S16 & S17 & S18 & S19 & S20 & Total \% \\
\hline Tl(1) F1 & 2 & 1 & 2 & 2 & 2 & 2 & 2 & 2 & 1 & 2 & 1 & 1 & 1 & 2 & 1 & 2 & 2 & 2 & 1 & 1 & 80 \\
\hline Tl(2) Fl & 2 & 0 & 1 & 2 & 0 & 1 & 2 & 1 & 0 & 1 & 0 & 1 & 0 & 2 & 1 & 1 & 1 & 0 & 1 & 0 & 43 \\
\hline Tl(3) F2 & 2 & 0 & 1 & 2 & 0 & 1 & 2 & 1 & 0 & 1 & 0 & 1 & 0 & 2 & 1 & 1 & 1 & 0 & 1 & 0 & 52 \\
\hline Tl(4) F2 & 1 & 0 & 1 & 1 & 1 & 1 & 1 & 0 & 1 & 0 & 2 & 0 & 0 & 0 & 2 & 1 & 2 & 0 & 0 & 2 & 40 \\
\hline Tl(5) F2 & 2 & 1 & 1 & 2 & 1 & 0 & 2 & 0 & 1 & 1 & 1 & 0 & 1 & 0 & 1 & 1 & 0 & 0 & 1 & 1 & 43 \\
\hline Tl(6) F3 & 2 & 1 & 0 & 2 & 1 & 2 & 1 & 0 & 0 & 1 & 1 & 1 & 1 & 1 & 2 & 1 & 1 & 0 & 0 & 0 & 45 \\
\hline Tl(7) F4 & 2 & 0 & 1 & 2 & 1 & 2 & 0 & 0 & 1 & 0 & 1 & 0 & 1 & 0 & 1 & 0 & 1 & 1 & 0 & 0 & 35 \\
\hline Tl(8) F4 & 2 & 1 & 1 & 2 & 1 & 2 & 2 & 2 & 0 & 2 & 2 & 1 & 1 & 0 & 1 & 0 & 2 & 0 & 0 & 0 & 56 \\
\hline Tl(9) F5 & 0 & 0 & 0 & 0 & 0 & 0 & 0 & 0 & 0 & 0 & 0 & 0 & 0 & 0 & 0 & 0 & 0 & 0 & 0 & 0 & 0 \\
\hline Tl(10) F5 & 2 & 0 & 0 & 2 & 0 & 2 & 0 & 0 & 0 & 0 & 0 & 0 & 0 & 0 & 0 & 0 & 0 & 0 & 0 & 0 & 15 \\
\hline Tn(n): Theorem (question), F: Facet, S: Student, Fl: Basic Knowledge, F2: Logical Status, F3: Summarization, F4: Generality, F5: Application \\
\hline
\end{tabular}

However, performance for the Application (F5) facet, about applicability of a proof in different situations, is low level (approximately 7\%). It is observed that the higher the comprehension level, the lower the students' comprehension percentages.

When each question is examined, the highest comprehension percentages occurred in Question 1 (80\%), regarding knowledge of terms used in a proof. The lowest comprehension level is for Question $9(0 \%)$, regarding conducting proofs in different ways. According to these results, it is observed that students comprehend prerequisite knowledge like definition, figures, and symbols, but are poorer at comprehending conducting proofs in different ways.

In Questions 3-5, in which transitions of logical relationships among proof steps are questioned, although students reached similar comprehension percentages, they are unsatisfactory. In each question, different comprehension percentages are seen. Accordingly, students do not have the same comprehension performance for all proof steps, and may comprehend one step transition, but not the next. Since the structure of proofs and each proof step has different functionality, this result is accepted as natural.

Question 6 in PCT-1 is about identifying critical steps on which proof is based. The performance percentage for Question 6 is also unsatisfactory (45\%). According to this result, although students comprehend basic information like definitions and symbols, they performed poorly on identifying the basic foundation of a proof. Question 6 asked, "According to you, which steps are the critical steps for this proof?". S17 answered; "3rd and 4th steps; because if we do not know the sum of interior angles of a triangle we cannot conduct the proof", showing that $\mathrm{S} 17$ understood the critical idea of the proof.

For Question 10, by using the given proof in PCT-1, students were asked to show the sum of exterior angles of a quadrilateral. Only three students could answer this (S1, S4, S6). After the classroom intervention, during student interviews they confessed that they saw this proof before and could therefore answer it. S6's answer is presented in Figure 3 (Student's written answer in Figure 3: Since there are four of this line 4.180 $=720^{\circ}$. Among $360^{\circ}$ of it remains inside so that $720-360=360$ belongs to exterior angles and the sum of exterior angles is $360^{\circ}$ ). 


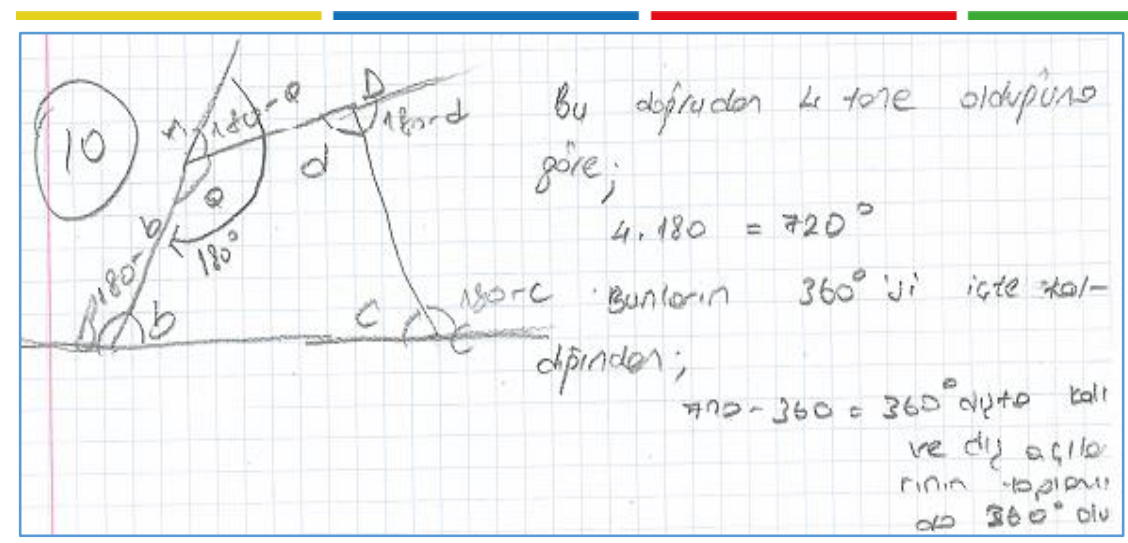

Figure 3. Answer by S6 for PCT-1 Question 10

Table 4 presents the proof comprehension levels for each students according to according to determined percentages. As explained before students are labelled as low with performance percentages of $0-33 \%$, medium with $34-66 \%$ and high with $67-100 \%$.

Table 4. PCT-1 participant evaluation results

\begin{tabular}{|c|c|c|c|c|}
\hline Level & $\begin{array}{l}\text { Comprehending } \\
\text { Degree }\end{array}$ & Student & Frequency & Percentage \\
\hline \multirow{3}{*}{ Surface } & Low & $\mathrm{S} 2, \mathrm{~S} 9, \mathrm{~S} 11, \mathrm{~S} 13, \mathrm{~S} 20$ & 5 & 25 \\
\hline & Medium & $\mathrm{S} 5, \mathrm{~S} 12, \mathrm{~S} 15, \mathrm{~S} 18, \mathrm{~S} 19$ & 5 & 25 \\
\hline & High & $\mathrm{S} 1, \mathrm{~S} 3, \mathrm{~S} 4, \mathrm{~S} 6, \mathrm{~S} 7, \mathrm{~S} 8, \mathrm{~S} 10, \mathrm{~S} 14, \mathrm{~S} 16, \mathrm{~S} 17$ & 10 & 50 \\
\hline \multirow{3}{*}{$\begin{array}{l}\text { Recognizing } \\
\text { Elements }\end{array}$} & Low & $\mathrm{S} 2, \mathrm{~S} 5, \mathrm{~S} 8, \mathrm{~S} 10, \mathrm{~S} 12, \mathrm{~S} 13, \mathrm{~S} 14, \mathrm{~S} 18, \mathrm{~S} 19$ & 9 & 45 \\
\hline & Medium & $\mathrm{S} 1, \mathrm{~S} 4, \mathrm{~S} 6, \mathrm{~S} 9, \mathrm{~S} 16, \mathrm{~S} 17$ & 6 & 30 \\
\hline & High & $\mathrm{S} 3, \mathrm{~S} 7, \mathrm{~S} 11, \mathrm{~S} 15, \mathrm{~S} 20$ & 5 & 25 \\
\hline \multirow{3}{*}{$\begin{array}{l}\text { Chaining } \\
\text { Elements }\end{array}$} & Low & S2,S3,S7,S8,S9,S10,S13,S18,S19,S20 & 10 & 50 \\
\hline & Medium & $\mathrm{S} 5, \mathrm{~S} 11, \mathrm{~S} 12, \mathrm{~S} 14, \mathrm{~S} 16, \mathrm{~S} 17$ & 6 & 30 \\
\hline & High & $\mathrm{S} 1, \mathrm{~S} 4, \mathrm{~S} 6, \mathrm{~S} 15$ & 4 & 20 \\
\hline \multirow{3}{*}{ Encapsulation } & Low & $\begin{array}{l}\text { S2,S3,S5,S7,S8,S9,S10,S11,S12,S13, } \\
\text { S14,S15,S16,S17,S18,S19,S20 }\end{array}$ & 17 & 85 \\
\hline & Medium & $\mathrm{S} 1, \mathrm{~S} 4, \mathrm{~S} 6$ & 3 & 15 \\
\hline & High & - & 0 & 0 \\
\hline
\end{tabular}

Table 4 shows that student percentages at high comprehension levels are mostly at the Surface level, and low comprehension levels found mostly at the Encapsulation level which involves conducting proofs in different ways. Aligned with this result, student comprehension performance descends from Surface level to Encapsulation. It is observed that for PCT-1's theorems and proofs, students comprehend definitions and symbols in proofs, but inadequately performed in levels involving high degrees of comprehension. 


\subsection{Analysis Results: PCT-2}

PCT-2 was prepared for the quadrilateral unit given in 'process standard 2' of the 11th grade geometry curriculum (MoNE, 2010). The theorem is "the measure of the angle of an intersection of bisectors belonging to two adjacent interior angles of a quadrilateral is equal to half the sum of the other two angles", and is given in the explanation part of the curriculum. Ten questions were written for the proof in PCT-2. Students' answers are evaluated according to the related facets and presented in Table 5 .

When Table 5 is examined, participant performance percentage is seen as medium (64\%) for Questions 1-3 on the Basic Knowledge (F1) facet, regarding symbols and statements of proof. The performances for the Logical Status (F2) facet, on comprehension of transition among proof steps, are of medium level (approximately 37\% where $(30+35+45) / 3$ ), but low level for the Summarization (F3) facet (8\%), on comprehension of critical ideas in a proof, the Generality (F4) facet (11\%), on the accuracy of proof, and the Application (F5) facet (0\%), on the applicability of a proof in different situations. Noteworthy is the Application facet where all students presented unsatisfactory performance, hence the percentage is zero.

Other findings reached from Table 5 are that when the comprehension level progresses, there is no identifiable pattern of movement, increasing or decreasing. A decrease is observed in the transition from Basic Knowledge to Logical Status to Summarization facets, but increases when passing through the Generality facet.

Table 5. PCT-2 scores \& total percentages by facet

\begin{tabular}{|c|c|c|c|c|c|c|c|c|c|c|c|c|c|c|c|c|c|c|c|c|c|}
\hline РCT-2 & S1 & $\mathrm{S2}$ & S3 & S4 & S5 & S6 & S7 & S8 & SS & $\mathrm{SlC}$ & S11 & S12 & S13 & S14 & S15 & S16 & S17 & S18 & S19 & S20 & Total $\%$ \\
\hline T2(1) Fl & 1 & 1 & 1 & 0 & 1 & 1 & 0 & 1 & 0 & 0 & 0 & 0 & 0 & 0 & 1 & 1 & 0 & 0 & 0 & 0 & 20 \\
\hline $\mathrm{T} 2(2) \mathrm{Fl}$ & 2 & 2 & 2 & 2 & 2 & 2 & 1 & 2 & 2 & 2 & 2 & 1 & 2 & 2 & 2 & 2 & 1 & 2 & 1 & 1 & 83 \\
\hline T2(3) F1 & 2 & 2 & 2 & 2 & 2 & 2 & 1 & 2 & 2 & 2 & 2 & 2 & 2 & 2 & 2 & 2 & 1 & 2 & 1 & 1 & 90 \\
\hline $\mathrm{T}$ 2(4) F2 & 1 & 0 & 1 & 2 & 0 & 0 & 0 & 0 & 0 & 1 & 0 & 2 & 0 & 0 & 2 & 2 & 0 & 0 & 0 & 1 & 30 \\
\hline T2(5) F2 & 1 & 0 & 1 & 2 & 0 & 0 & 0 & 0 & 0 & 1 & 0 & 2 & 1 & 0 & 2 & 2 & 0 & 0 & 1 & 1 & 35 \\
\hline T2(6) F2 & 1 & 0 & 1 & 2 & 0 & 0 & 1 & 1 & 1 & 1 & 1 & 1 & 2 & 1 & 2 & 2 & 0 & 0 & 1 & 1 & 45 \\
\hline T2(7) F3 & 1 & 0 & 0 & 0 & 0 & 1 & 0 & 0 & 0 & 1 & 0 & 0 & 0 & 0 & 0 & 0 & 0 & 0 & 0 & 0 & 8 \\
\hline T2(8) F4 & 1 & 0 & 0 & 0 & 0 & 1 & 0 & 0 & 0 & 1 & 0 & 0 & 0 & 0 & 0 & 0 & 0 & 0 & 0 & 0 & 8 \\
\hline $\mathrm{T} 2(9) \mathrm{F} 4$ & 1 & 0 & 1 & 1 & 1 & 1 & 0 & 1 & 1 & 1 & 0 & 0 & 0 & 1 & 1 & 1 & 0 & 0 & 0 & 0 & 28 \\
\hline $\mathrm{T} 2(10) \mathrm{F} 5$ & 0 & 0 & 0 & 0 & 0 & 0 & 0 & 0 & 0 & 0 & 0 & 0 & 0 & 0 & 0 & 0 & 0 & 0 & 0 & 0 & 0 \\
\hline
\end{tabular}

It is natural to find no linear decrease or increase on comprehension performance towards different facets when the multidimensional structure of proof and proving is considered.

Question 1 in PCT-2 is about defining the term, "bisector". The comprehension level for Question 1 is the lowest (20\%) among all questions on the Basic Knowledge facet, and the highest is for Question $3(90 \%)$ regarding the sum of interior angles of quadrilaterals. Since the proof used in PCT-1 is about sum of interior angles of a quadrilateral, the result from Question 3 in PCT-2 may reflect PCT-1. As an example, S5's answer to Question 3 ("Do you agree with the equality $\mathrm{m}(A)+\mathrm{m}(B)+\mathrm{m}(C)+\mathrm{m}(D)=360$ degrees given in the proof? Why?") was "I agree, because the angles $\mathrm{m}(A), \mathrm{m}(B), \mathrm{m}(C), \mathrm{m}(D)$ construct a quadrilateral. Since the sum of interior angles is 360 degrees, then $\mathrm{m}(A)+\mathrm{m}(B)+\mathrm{m}(C)+\mathrm{m}(D)=360$ degrees". As seen, student S5 comprehended the basic knowledge needed to complete the proof.

PCT-2 asks the proof validity when the bisector of angles are drawn from different vertices. The comprehension level percentages are the lowest (30\%) for Questions 4-6, which 
relate to the Logical Status facet. S4 responded "No" for Question 4 ("what if the bisectors of theorem intersect outside of the quadrilateral region, is the theorem still true?"). S4's explanation is shown in Figure 4.

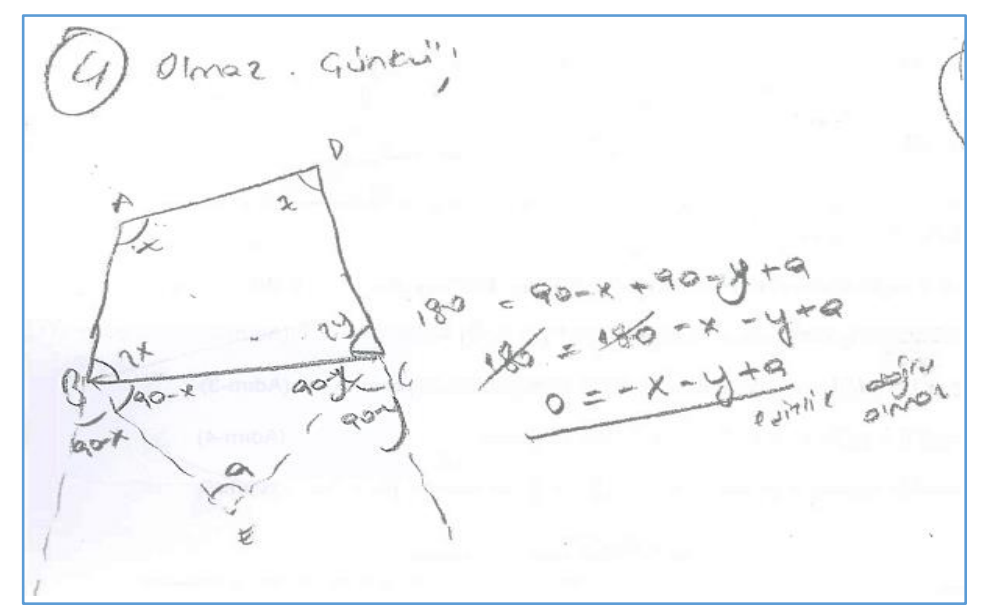

Figure 4. Answer by S4 for PCT-2 Question 4

According to results for the Logical Status facet, it is understood that students could not comprehend the logical relationships of proof steps. Considering the percentages for Question 1 , it may be concluded that students lack understanding about bisector which affects the next steps' comprehension about bisector.

In PCT-2 Question 10, students must prove the given theorem in different ways, but no student could answer this question. S10's answer (see Figure 5) shows the proof simply conducted in the same way again. Student comprehension levels are individually presented in Table 6 based on the data for each facet and levels, and the table shows each student's performance level and degree.

Table 6 shows that most students present high comprehension performance for Surface Level; the knowledge of statements and symbols for proofs. However, in other comprehension levels, percentages decreased from $20 \%$ to $0 \%$. Different from PCT-1, results for PCT-2 present a decreasing pattern for different comprehension levels. In the Encapsulation level, which involves proving a proof in a different way or conducting another proof depending on previous proof comprehension, no high or medium degree of comprehension occurred.

Another remarkable result is that the same student may present different performances degrees for different comprehension levels (e.g., S17 is medium for Surface level, but low for Recognizing Elements). Accordingly, it can be concluded that students did not perform the same for all stages of a proof. 


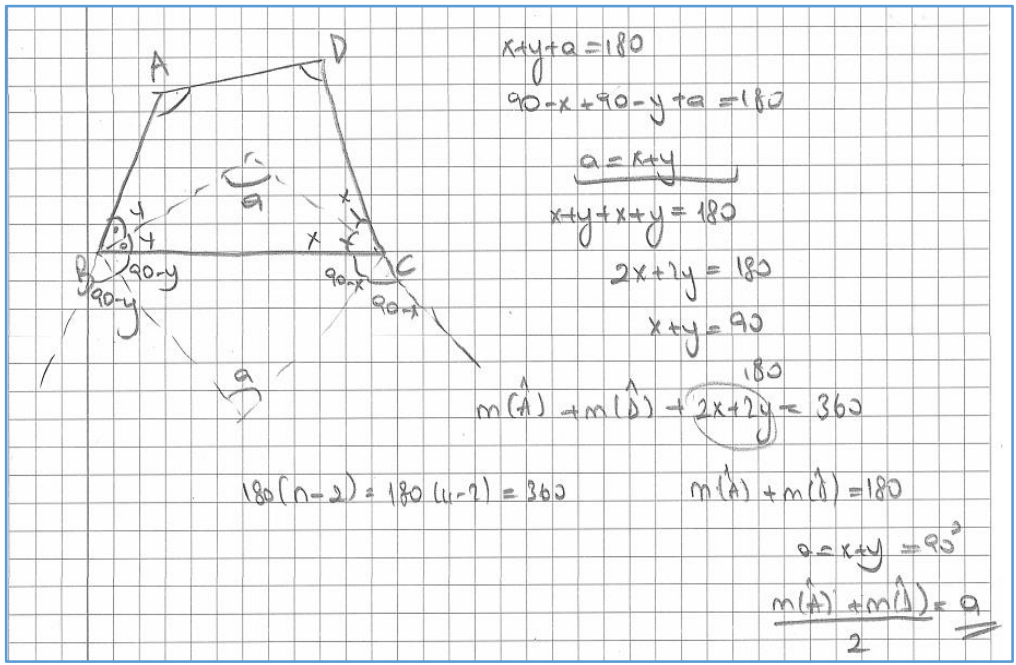

Figure 5. Answer by S10 for PCT-2 Question 10

Table 6. PCT-2 participant evaluation results

\begin{tabular}{|c|c|c|c|c|}
\hline Level & $\begin{array}{l}\text { Comprehending } \\
\text { Degree }\end{array}$ & Student & Frequency & Percentage \\
\hline \multirow{3}{*}{ Surface } & Low & $\mathrm{S} 7, \mathrm{~S} 19, \mathrm{~S} 20$ & 3 & 15 \\
\hline & Medium & S17 & 1 & 5 \\
\hline & High & $\begin{array}{l}\text { S1,S2,S3,S4,S5,S6,S8,S9,S10,S11, } \\
\text { S12,S13,S14,S16,S18 }\end{array}$ & 15 & 75 \\
\hline \multirow{3}{*}{$\begin{array}{l}\text { Recognizing } \\
\text { Elements }\end{array}$} & Low & $\begin{array}{l}\text { S2,S5,S6,S7,S8,S9,S10,S11,S13,S14, } \\
\text { S17,S18,S19 }\end{array}$ & 12 & 65 \\
\hline & Medium & $\mathrm{S} 1, \mathrm{~S} 3, \mathrm{~S} 10, \mathrm{~S} 20$ & 4 & 20 \\
\hline & High & $\mathrm{S} 4, \mathrm{~S} 12, \mathrm{~S} 15, \mathrm{~S} 16$ & 4 & 20 \\
\hline \multirow{3}{*}{$\begin{array}{l}\text { Chaining } \\
\text { Elements }\end{array}$} & Low & $\begin{array}{l}\text { S2,S3,S4,S5,S6,S7,S8,S9,S10,S11, } \\
\text { S12,S13,S14,S15,S16,S18,S19,S20 }\end{array}$ & 18 & 90 \\
\hline & Medium & $\mathrm{S} 1, \mathrm{~S} 17$ & 2 & 10 \\
\hline & High & - & 0 & 0 \\
\hline \multirow{3}{*}{ Encapsulation } & Low & $\begin{array}{l}\mathrm{S} 1, \mathrm{~S} 2, \mathrm{~S} 3, \mathrm{~S} 4, \mathrm{~S} 5, \mathrm{~S} 6, \mathrm{~S} 7, \mathrm{~S} 8, \mathrm{~S} 9, \mathrm{~S} 10, \mathrm{~S} 11 \\
\mathrm{~S} 12, \mathrm{~S} 13, \mathrm{~S} 14, \mathrm{~S} 15, \mathrm{~S} 16, \mathrm{~S} 17, \mathrm{~S} 18, \mathrm{~S} 19, \mathrm{~S} 20\end{array}$ & 20 & 100 \\
\hline & Medium & - & 0 & 0 \\
\hline & High & - & 0 & 0 \\
\hline
\end{tabular}

\subsection{Analysis Results: PCT-3}

PCT-3 was prepared for quadrilateral unit in 'process standard 2' of the 11th grade geometry curriculum (MEB, 2010). The theorem is "Prove that in any quadrilateral ABCD, if the diagonals are perpendicular to each other, then the sum of the square of opposite sides of the quadrilateral are equal", and is given in the geometry curriculum explanation. The 10 
questions related with the proof and students' scores according to determined facets are presented in Table 7.

Table 7. PCT-3 scores \& total percentages by facet

\begin{tabular}{lccccccccccccccccccccc} 
PCT-3 & S1 & S2 & S3 & S4 & S5 & S6 & S7 & S8 & S9 & S10 & S11 & S12 & S13 & S14 & S15 & S16 & S17 & S18 & S19 & S20 & Total\% \\
\hline T3(1) F1 & 1 & 1 & 1 & 1 & 1 & 1 & 2 & 1 & 1 & 1 & 1 & 2 & 1 & 2 & 1 & 1 & 1 & 1 & 1 & 0 & 53 \\
\hline T3(2) F1 & 0 & 0 & 0 & 0 & 1 & 1 & 1 & 0 & 0 & 0 & 0 & 0 & 0 & 2 & 1 & 1 & 0 & 0 & 0 & 0 & 18 \\
\hline T3(3) F2 & 2 & 1 & 2 & 2 & 2 & 2 & 2 & 2 & 1 & 2 & 2 & 2 & 1 & 2 & 2 & 2 & 2 & 1 & 1 & 2 & 87 \\
\hline T3(4) F2 & 1 & 0 & 1 & 0 & 2 & 2 & 0 & 1 & 0 & 1 & 0 & 1 & 1 & 0 & 1 & 1 & 0 & 1 & 0 & 1 & 37 \\
\hline T3(5) F2 & 2 & 1 & 1 & 2 & 2 & 2 & 2 & 1 & 2 & 2 & 2 & 2 & 1 & 2 & 1 & 2 & 2 & 1 & 1 & 1 & 80 \\
\hline T3(6) F2 & 1 & 0 & 1 & 1 & 0 & 1 & 0 & 1 & 1 & 1 & 0 & 0 & 1 & 1 & 1 & 1 & 1 & 0 & 1 & 1 & 35 \\
\hline T3(7) F3 & 1 & 0 & 1 & 1 & 1 & 1 & 1 & 2 & 0 & 1 & 1 & 1 & 0 & 1 & 1 & 0 & 1 & 0 & 1 & 1 & 40 \\
\hline T3(8) F4 & 0 & 1 & 0 & 1 & 0 & 1 & 1 & 1 & 0 & 1 & 0 & 1 & 0 & 1 & 0 & 1 & 0 & 1 & 0 & 1 & 27 \\
\hline T3(9) F4 & 1 & 0 & 0 & 0 & 0 & 1 & 0 & 1 & 0 & 1 & 0 & 0 & 0 & 1 & 0 & 0 & 0 & 0 & 0 & 1 & 15 \\
\hline T3(10) F5 & 0 & 0 & 0 & 0 & 0 & 0 & 0 & 0 & 0 & 0 & 0 & 0 & 0 & 0 & 0 & 0 & 0 & 0 & 0 & 0 & 0 \\
\hline Tn(n): Theorem (question), F: Facet, S: Student, Fl: Basic Knowledge, F2: Logical Status, F3: Summarization, F4: Generality, F5: Application \\
\hline
\end{tabular}

Table 7 shows participant performance percentage as medium (53\%) for Question 1 on Basic Knowledge (F1) regarding information about symbols and statements of proof, but very low $(18 \%)$ for Question 2. The highest performance percentage (approximately $60 \%$ where $(87+37+80+35) / 4)$ was for the Logical Status (F2) facet, regarding comprehension of passes among proof steps. Low level performance is also seen for Summarization (F3) facet (40\%), regarding comprehension of critical ideas in a proof, Generality (F4) facet $(21 \%)$ on accuracy of proof, and Application (F5) facet (0\%), regarding applicability of a proof in different situations. In Table 6, similar to PCT-2, no students present satisfactory performances in the Application facet.

The most remarkable result is that although students presented lower performances in the Basic Knowledge facet, regarding comprehending statements and symbols in proofs, students presented higher comprehending performances for the Logical Status facet which involves comprehending transition among proof steps. This result shows that although students could not comprehend the basic concepts, they could comprehend the next stages of the proof.

From Question 1 and 2 related to Basic Knowledge facet, the lowest comprehending percentage is $18 \%$ for Question 2. Only one student answered correctly about whether diagonals of a quadrilateral are always perpendicular to each other. S14 answered "No, not intersect perpendicular. Because it changes from quadrilateral to another type of quadrilateral. In some quadrilaterals they intersect perpendicular, but not all of them".

However, in the same facet a 53\% comprehension level was obtained for Question 1, regarding Pythagorean relation which students are familiar with. Accordingly, it can be concluded that students may not perform at the same comprehension level for basic concepts given in a proof.

High levels of comprehension were seen in Question 3 (87\%) and Question 5 (80\%), regarding transitions among proof steps, but low levels were seen in Question $4(37 \%)$ and Question $6(35 \%)$, with the same logical perspectives which questioned the possibility of conducting a proof in different ways. This result is remarkable because of the distinct variation seen in the same comprehension facet, showing that students can interpret given steps but cannot produce these steps in different ways.

Question 6 asked in cases where diagonals intersect perpendicularly, would it be possible to produce a proof, and Question 7 asked what critical steps a proof depends on. Although the 
questions are in different comprehension facets, neither had satisfactory comprehension levels (Q6: 35\%, Q7: 40\%), with results correlated as the questions are related.

Similar to PCT-2, Question 10 involved conducting proof in different ways for the Application facet, and no student could answer it. Students faced difficulties in this facet as it measures the ability of knowing how to apply a proposition in another situation, and making this facet the highest comprehension level.

Table 8 presents students' individual levels of comprehension based on the data obtained for facets needed to transition among the proof comprehension levels. At the Surface level, the percentage of students with high comprehension is very low (10\%), with students having difficulties with basic concepts needed for conducting a proof.

The percentages of high (50\%) and medium (40\%) level comprehension in Recognizing Elements where there is a logical relationship is more than the percentages of low comprehension (10\%). This result reveals the parts of the proofs comprehended.

In PCT-3, the high comprehension degree (50\%) is higher than both PCT-1 (25\%) and PCT-2 (20\%). Different to PCT1 and PCT-2, the highest comprehension degree for PCT-3 occurs in the Recognizing Elements level; however, the comprehension degree was still inadequate at $50 \%$. The reason may be the effect of high percentages of low degree comprehension at the Surface level. It may be considered that knowing the basic concepts is necessary for the advanced comprehension levels, but is not enough.

Table 8. PCT-3 participant evaluation results

\begin{tabular}{|c|c|c|c|c|}
\hline Level & $\begin{array}{l}\text { Comprehending } \\
\text { Degree }\end{array}$ & Student & Frequency & Percentage \\
\hline \multirow{3}{*}{ Surface } & Low & $\begin{array}{l}\text { S1,S2,S3,S4,S8,S9,S10,S11,S12,S13, } \\
\text { S17,S18,S19,S20 }\end{array}$ & 14 & 70 \\
\hline & Medium & S5,S6,S15,S16 & 4 & 20 \\
\hline & High & $\mathrm{S} 7, \mathrm{~S} 14$ & 2 & 10 \\
\hline \multirow{3}{*}{$\begin{array}{l}\text { Recognizing } \\
\text { Elements }\end{array}$} & Low & $\mathrm{S} 2, \mathrm{~S} 19$ & 2 & 10 \\
\hline & Medium & $\mathrm{S} 3, \mathrm{~S} 8, \mathrm{~S} 9, \mathrm{~S} 13, \mathrm{~S} 14, \mathrm{~S} 15, \mathrm{~S} 18, \mathrm{~S} 20$ & 8 & 40 \\
\hline & High & $\mathrm{S} 1, \mathrm{~S} 4, \mathrm{~S} 5, \mathrm{~S} 6, \mathrm{~S} 7, \mathrm{~S} 10, \mathrm{~S} 11, \mathrm{~S} 12, \mathrm{~S} 16, \mathrm{~S} 17$ & 10 & 50 \\
\hline \multirow{3}{*}{$\begin{array}{l}\text { Chaining } \\
\text { Elements }\end{array}$} & Low & $\begin{array}{l}\text { S1,S2,S3,S9,S10,S11,S13,S15,S16, } \\
\text { S17,S18,S19,S20 }\end{array}$ & 13 & 65 \\
\hline & Medium & $\mathrm{S} 4, \mathrm{~S} 5, \mathrm{~S} 6, \mathrm{~S} 7, \mathrm{~S} 12, \mathrm{~S} 14$ & 6 & 30 \\
\hline & High & S8 & 1 & 5 \\
\hline \multirow{3}{*}{ Encapsulation } & Low & $\begin{array}{l}\mathrm{S} 1, \mathrm{~S} 2, \mathrm{~S} 3, \mathrm{~S} 4, \mathrm{~S} 5, \mathrm{~S} 6, \mathrm{~S} 7, \mathrm{~S} 8, \mathrm{~S} 9, \mathrm{~S} 10, \mathrm{~S} 11, \\
\mathrm{~S} 12, \mathrm{~S} 13, \mathrm{~S} 14, \mathrm{~S} 15, \mathrm{~S} 16, \mathrm{~S} 17, \mathrm{~S} 18, \mathrm{~S} 19, \mathrm{~S} 20\end{array}$ & 20 & 100 \\
\hline & Medium & - & 0 & 0 \\
\hline & High & - & 0 & 0 \\
\hline
\end{tabular}


In the Chaining Elements level, only one student shows a high comprehension level, whereas six students presented medium level comprehension. In S8's high performance for Question 9 ("Explain the conducted proof in your own words"), S8 explained the conducted proof in his/her own words, but stayed with the given proof; hence, only 1 point was scored (see Figure 6) (student's writings: first of all by using Pythagorean [formula] on triangle DEC we get $n^{2}+l^{2}=d^{2}$ Later I use same presentation in triangle AEB $m^{2}+k^{2}=c^{2}$. These equalities are added and $n^{2}+l^{2}+m^{2}+k^{2}=d^{2}+c^{2}$. Pythagorean [formula] is used in DEA triangle $n^{2}+m^{2}$ $=b^{2}$ and the same method is applied on the other triangle CEB $l^{2}+k^{2}=a^{a^{2}}$. These equalities are added and $n^{2}+m^{2}+l^{2}+k^{2}=a^{2}+b^{2}$. Therefore $d^{2}+c^{2}$ and $a^{2}+b^{2}$ are same and $d^{2}+c^{2}=a^{2}+b^{2}$ ) .

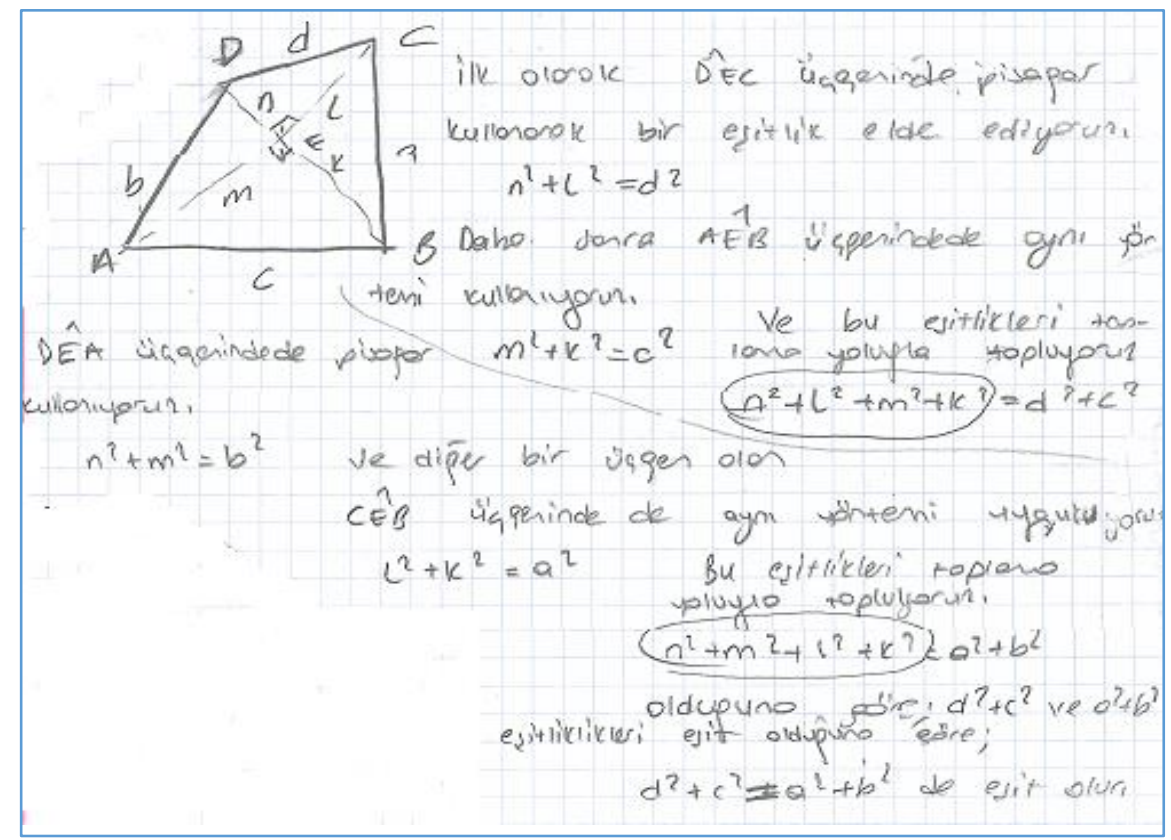

Figure 6. Answer by S8 for PCT-3 Question 9

In the Encapsulation level, regarding proving differently, no student achieves medium or high level comprehension, only low.

\subsection{Analysis Results: PCT-4}

PCT-4 was prepared for the explanation of 'process standard 3' of the 11th grade geometry curriculum (MEB, 2010); that is, "Prove that the area of convex quadrilateral region is equal to half of the multiplication of length of the diagonal by sinus of angle between diagonals". There are 11 questions in PCT-4, evaluated based on the determined facets, with scores presented in Table 9. 
Table 9. PCT-4 scores \& total percentages by facet

\begin{tabular}{|c|c|c|c|c|c|c|c|c|c|c|c|c|c|c|c|c|c|c|c|c|c|c|}
\hline PCT-4 & Sl & S2 & S3 & S4 & S5 & S6 & S7 & S & 8 & S9 & S10 & Sll & S12 & S13 & S14 & S15 & S16 & S17 & S18 & S19 & $\mathrm{S20}$ & Total $\%$ \\
\hline T4(1) F1 & 0 & 0 & 0 & 1 & 1 & 1 & 1 & 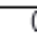 & 0 & 1 & 0 & 1 & 1 & 1 & 1 & 0 & 1 & 1 & 1 & 1 & 0 & 35 \\
\hline $\mathrm{T} 4(2) \mathrm{Fl}$ & 1 & 1 & 1 & 0 & 1 & 1 & 0 & . & 1 & 1 & 1 & 0 & 0 & 0 & 0 & 1 & 1 & 0 & 0 & 0 & 1 & 22 \\
\hline $\mathrm{T} 4(3) \mathrm{F} 2$ & 2 & 2 & 2 & 2 & 2 & 2 & 2 & 2 & 2 & 2 & 2 & 2 & 2 & 2 & 2 & 2 & 2 & 2 & 2 & 2 & 2 & 100 \\
\hline $\mathrm{T} 4(4) \mathrm{F} 2$ & 2 & 2 & 2 & 2 & 2 & 2 & 2 & 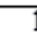 & 1 & 2 & 1 & 0 & 2 & 1 & 1 & 1 & 0 & 1 & 1 & 1 & 1 & 67 \\
\hline $\mathrm{T} 4(5) \mathrm{F} 2$ & 2 & 2 & 2 & 2 & 2 & 2 & 2 & . & 1 & 2 & 2 & 0 & 2 & 1 & 1 & 1 & 0 & 1 & 1 & 1 & 1 & 67 \\
\hline $\mathrm{T} 4(6) \mathrm{F} 2$ & 2 & 2 & 2 & 2 & 2 & 2 & 2 & 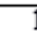 & 1 & 2 & 2 & 1 & 2 & 1 & 2 & 1 & 2 & 1 & 2 & 1 & 2 & 85 \\
\hline $\mathrm{T} 4(7) \mathrm{F} 2$ & 1 & 1 & 1 & 1 & 1 & 1 & 1 & 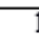 & 1 & 1 & 1 & 1 & 1 & 0 & 1 & 0 & 0 & 0 & 0 & 0 & 1 & 37 \\
\hline T4(8) F3 & 1 & 0 & 1 & 1 & 1 & 2 & 0 & 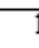 & 1 & 1 & 1 & 1 & 0 & 1 & 1 & 1 & 1 & 0 & 1 & 0 & 1 & 35 \\
\hline $\mathrm{T} 4(9) \mathrm{F} 4$ & 0 & 1 & 1 & 1 & 0 & 1 & 0 & . & 1 & 1 & 1 & 1 & 0 & 1 & 1 & 1 & 1 & 1 & 1 & 0 & 1 & 33 \\
\hline $\mathrm{T} 4(10) \mathrm{F} 4$ & 1 & 1 & 2 & 1 & 1 & 2 & 0 & 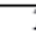 & 2 & 0 & 1 & 1 & 2 & 0 & 0 & 1 & 1 & 1 & 1 & 0 & 2 & 50 \\
\hline T4(11) F5 & 0 & 0 & 0 & 0 & 0 & 0 & 0 & 7 & 0 & 0 & 0 & 0 & 0 & 0 & 0 & 0 & 0 & 0 & 0 & 0 & 0 & 0 \\
\hline
\end{tabular}

Questions 1-3 of PCT-4 are on Basic Knowledge, involving statements of proofs and knowledge of symbols such as knowledge of convex, and sinus. However, the percentage of comprehension level is very low for Question 1 (35\%) and Question $2(22 \%)$, but for Question 3 , all students reached high performance percentages. Question 2 is on sinus which is about trigonometry, and Question 1 asks the definition of "convex". Figure 7 shows student S19 supporting his/her definition with two shapes, identifying one as convex and one as concave. Due to this poor definition, S19 had Question 1 graded at 1 point (student's writing: If the vertices are bending towards outward it is [polygon] convex. If vertices are bending inward it is [polygon] concave.)

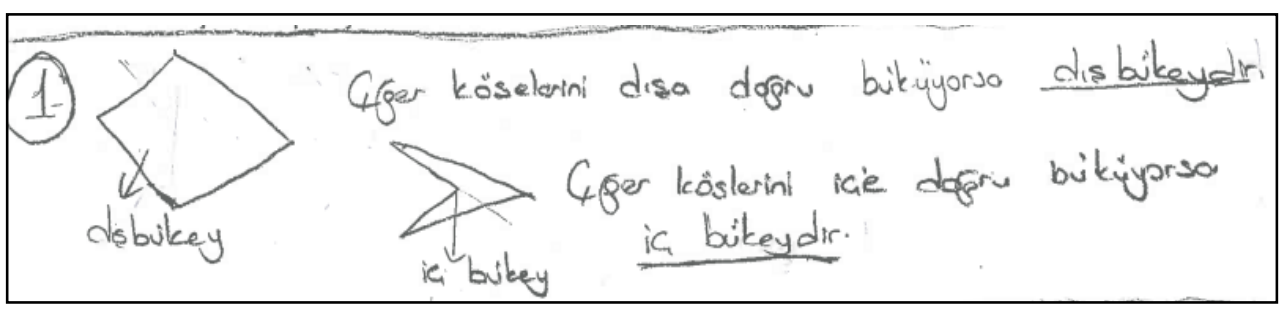

Figure 7. Answer by S19 for PCT-4 Question 1

In the Logical Status (F2) facet, where transitions among proof steps are questioned, although adequate comprehension degree is obtained for Questions 4-5 (67\%) and Question 6 (85\%), a low degree (37\%) of comprehension performance is observed for Question 7 (conducting a proof in different ways). This result shows consistency with other PCTs. For Question 7 ("Can you produce area formula for the quadrilateral by using AEB angle?"), one student answered:

Yes. $|B D|$ sides is 180 degrees and let AEB angle be $x$, and also DEA angle $y$ then $x+y=180$ degrees. From this point we can use this method for the other sides, and combine all of them to find the area formula for the quadrilateral, which is $1 / 2 . A E$. BE. Sin (180-alpha). (S7)

Another result observed is the relationship between Questions 2 and 7. Both required trigonometry knowledge and students show low comprehension level on both (Q2: 22\%, Q7: $37 \%$ ), suggesting students have poor background trigonometry knowledge (taught in 10th grade). Medium comprehension levels are obtained for the Summarization facet (F3) (64\%), in 
which comprehending critical ideas are explained, and from Generalization facet (F4) in which the certainty of the proof is questioned (approximately $43 \%$ where $(33+50) / 2)$. Again, similar to PCT-2 and PCT-3, low comprehension performance is seen in the Application facet (F5), in which explained proofs can be applied in varied situations, with no students performing adequately.

As in PCT-3, although in some questions of PCT-4 students present medium or low comprehension, in total the highest comprehension is for the Logical Status facet. Based on the data gathered, each student's level of comprehension is presented in Table 10. At the Surface level, students mostly present medium comprehension level, with no students at low level. For the Recognizing Elements level, half of the students presents high comprehension level. It can therefore be concluded that students can recognize which properties should be applied to the proof or are able to identify logical order of statements.

Table 10. PCT-4 participant evaluation results

\begin{tabular}{|c|c|c|c|c|}
\hline Level & $\begin{array}{l}\text { Comprehending } \\
\text { Degree }\end{array}$ & Student & Frequency & Percentage \\
\hline \multirow{3}{*}{ Surface } & Low & - & 0 & 0 \\
\hline & Medium & $\begin{array}{l}\mathrm{S} 1, \mathrm{~S} 3, \mathrm{~S} 4, \mathrm{~S} 5, \mathrm{~S} 6, \mathrm{~S} 7, \mathrm{~S} 8, \mathrm{~S} 11, \mathrm{~S} 12, \mathrm{~S} 13, \\
\text { S14,S15,S16,S17,S18,S19,S20 }\end{array}$ & 17 & 85 \\
\hline & High & $\mathrm{S} 2, \mathrm{~S} 9, \mathrm{~S} 10$ & 3 & 15 \\
\hline \multirow{3}{*}{$\begin{array}{l}\text { Recognizing } \\
\text { Elements }\end{array}$} & Low & S11,S16 & 2 & 10 \\
\hline & Medium & $\mathrm{S} 8, \mathrm{~S} 13, \mathrm{~S} 14, \mathrm{~S} 15, \mathrm{~S} 17, \mathrm{~S} 18, \mathrm{~S} 19, \mathrm{~S} 20$ & 8 & 40 \\
\hline & High & $\mathrm{S} 1, \mathrm{~S} 2, \mathrm{~S} 3, \mathrm{~S} 4, \mathrm{~S} 5, \mathrm{~S} 6, \mathrm{~S} 7, \mathrm{~S} 9, \mathrm{~S} 10, \mathrm{~S} 12$ & 10 & 50 \\
\hline \multirow{3}{*}{$\begin{array}{l}\text { Chaining } \\
\text { Elements }\end{array}$} & Low & $\begin{array}{l}\text { S1,S2,S3,S4,S7,S9,S10,S11,S12, } \\
\text { S14,S15,S17,S18,S19,S20 }\end{array}$ & 15 & 75 \\
\hline & Medium & $\mathrm{S} 5, \mathrm{~S} 8, \mathrm{~S} 13, \mathrm{~S} 16$ & 4 & 20 \\
\hline & High & S6 & 1 & 5 \\
\hline \multirow{3}{*}{ Encapsulation } & Low & $\begin{array}{l}\mathrm{S} 1, \mathrm{~S} 2, \mathrm{~S} 3, \mathrm{~S} 4, \mathrm{~S} 5, \mathrm{~S} 6, \mathrm{~S} 7, \mathrm{~S} 8, \mathrm{~S} 9, \mathrm{~S} 10, \mathrm{~S} 11, \\
\mathrm{~S} 12, \mathrm{~S} 13, \mathrm{~S} 14, \mathrm{~S} 15, \mathrm{~S} 16, \mathrm{~S} 17, \mathrm{~S} 18, \mathrm{~S} 19, \mathrm{~S} 20\end{array}$ & 20 & 100 \\
\hline & Medium & - & 0 & 0 \\
\hline & High & - & 0 & 0 \\
\hline
\end{tabular}

According to Table 10, among the high comprehension levels, Recognizing Elements, which explains logical relationships of transition among proof steps, is the highest. As with most other PCTs (excluding PCT-1), no students achieves satisfactory comprehension at the Encapsulation level, with all achieving a low degree of comprehension. Although the results of PCT-4 shows no descending or ascending pattern, this is very normal when considering the multilayered structure of proof comprehension. 


\subsection{Analysis Results: PCT-5}

PCT-5 was prepared for the theorem "Prove that the area of quadrilateral is equal to half of the area of a quadrilateral whose midpoints of the edges are accepted as vertices", which is given as an explanation of 'process standard 3' of the 11th grade geometry curriculum (MoNE, 2010). Twelve questions were asked based on the theorem in PCT-5, with answers evaluated according to predetermined facets, and scores presented in Table 11.

Questions 1-5 of PCT-5 are about Basic Knowledge (F1) and the knowledge of statements and symbols of proofs, with a high level (84\%) of comprehension performance seen. Question 1 sees the highest level (90\%) in which students were asked the definition of "intermediate base".

One student answered fully (see Figure 8) with:

The line drawn from the midpoint of a side of the triangle through to other side that is parallel to the base is called the intermediate base. It is parallel to the base of the triangle so that if the intermediate base is ' $a$ ' then the base of the triangle is '2a'. (S11).

Table 11. PCT-5 scores \& total percentages by facet

\begin{tabular}{lccccccccccccccccccccc} 
PCT-5 & S1 & S2 & S3 & S4 & S5 & S6 & S7 & S8 & S9 & S10 & S1l & S12 & S13 & S14 & S15 & S16 & S17 & S18 & S19 & S20 & Total \% \\
\hline T5(1) F1 & 2 & 2 & 2 & 2 & 2 & 2 & 2 & 2 & 1 & 1 & 2 & 2 & 1 & 2 & 2 & 1 & 2 & 2 & 2 & 2 & 90 \\
\hline T5(2) F1 & 2 & 2 & 1 & 2 & 2 & 2 & 2 & 2 & 1 & 1 & 2 & 2 & 1 & 1 & 1 & 1 & 1 & 2 & 1 & 2 & 75 \\
\hline T5(3) F1 & 2 & 2 & 2 & 1 & 2 & 1 & 2 & 1 & 1 & 1 & 2 & 2 & 1 & 1 & 1 & 2 & 1 & 2 & 1 & 2 & 74 \\
\hline T5(4) F1 & 2 & 2 & 1 & 2 & 2 & 2 & 2 & 1 & 1 & 2 & 2 & 2 & 1 & 1 & 1 & 1 & 1 & 2 & 1 & 2 & 75 \\
\hline T5(5) F1 & 2 & 2 & 1 & 2 & 2 & 1 & 2 & 2 & 1 & 1 & 2 & 2 & 1 & 1 & 1 & 2 & 1 & 2 & 1 & 2 & 76 \\
\hline T5(6) F2 & 2 & 2 & 1 & 2 & 1 & 2 & 1 & 1 & 1 & 2 & 1 & 2 & 2 & 2 & 1 & 2 & 2 & 1 & 2 & 1 & 78 \\
\hline T5(7) F2 & 2 & 2 & 1 & 2 & 2 & 2 & 1 & 2 & 2 & 2 & 2 & 2 & 2 & 2 & 2 & 2 & 1 & 2 & 1 & 2 & 90 \\
\hline T5(8) F2 & 0 & 1 & 0 & 1 & 1 & 1 & 0 & 1 & 0 & 0 & 0 & 1 & 1 & 1 & 0 & 1 & 1 & 0 & 0 & 1 & 35 \\
\hline T5(9) F2 & 1 & 1 & 1 & 1 & 0 & 2 & 1 & 2 & 0 & 1 & 0 & 1 & 1 & 1 & 1 & 1 & 2 & 0 & 1 & 1 & 45 \\
\hline T5(10) F3 & 1 & 0 & 1 & 1 & 0 & 2 & 1 & 1 & 1 & 1 & 0 & 1 & 1 & 0 & 0 & 1 & 1 & 1 & 1 & 2 & 40 \\
\hline T5(11) F4 & 1 & 1 & 0 & 1 & 1 & 1 & 1 & 1 & 1 & 0 & 1 & 0 & 1 & 0 & 1 & 0 & 0 & 1 & 1 & 1 & 34 \\
\hline T5(12) F5 & 0 & 0 & 0 & 0 & 0 & 0 & 0 & 0 & 0 & 0 & 0 & 0 & 0 & 0 & 0 & 0 & 0 & 0 & 0 & 0 & 0 \\
\hline Tn(n): Theorem (question), F: Facet, S: Student, Fl: Basic Knowledge, F2: Logical Status, F3: Summarization, F4: Generality, F5: Application
\end{tabular}

Accordingly, it can be concluded that students comprehend intermediate base from the 10th grade. In the Basic Knowledge facet, Questions 2-5 are all similar and results show students' comprehension levels as close to each other and therefore consistent.

In Questions 6-9 of the Logical Status facet (F2), regarding transition among proof steps, a medium level $(62 \%$ where $(78+90+35+45) / 4)$ of comprehension performance is seen, but upon a question-based examination, various percentages of comprehension performances occurred. For instance, in Question 7 regarding common parenthesis, the highest degree (90\%) of comprehension is seen, but in Question 9 regarding premises, only a medium level $(45 \%)$ of comprehension is obtained. 


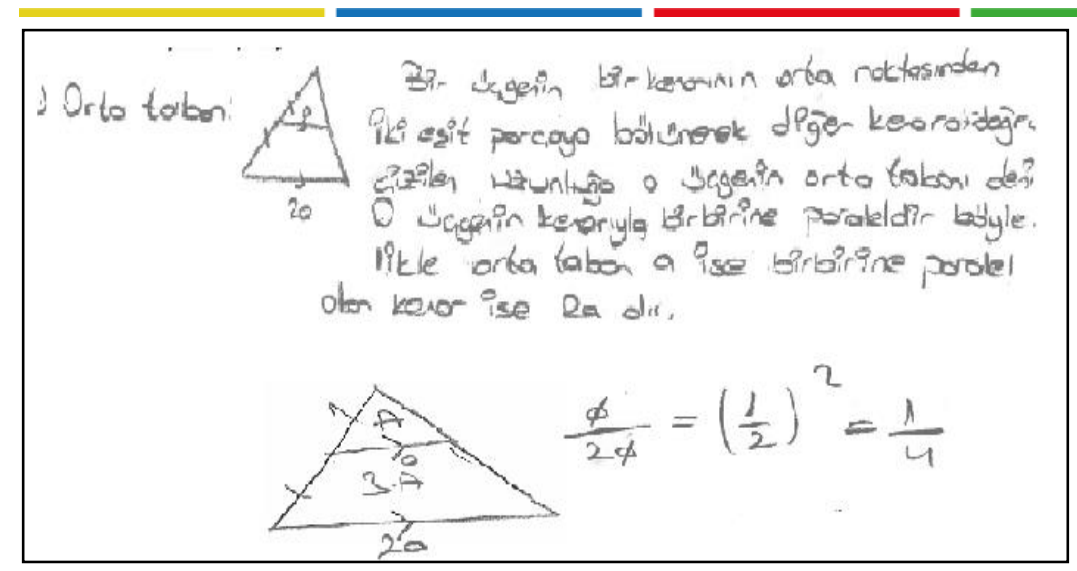

Figure 8. Answer by S11 PCT-5 Question 1

Accordingly, it can be deduced that students comprehended combining the giving parts of a proof; however, they could not decide which parts are necessary for proving. As an example, a student answered Question 9 regarding identifying which premises are necessary for the conducted proof, as "The equality of the sides should be given" (S9).

As with the other interventions, in PCT-5 no student conducted a proof in a different way, resulting in $0 \%$ for the degree of comprehension of the Application facet. Students' comprehension percentages are presented in Table 12 based on the scores in each facet.

Table 12. PCT-5 participant evaluation results

\begin{tabular}{|c|c|c|c|c|}
\hline Level & $\begin{array}{l}\text { Comprehending } \\
\text { Degree }\end{array}$ & Student & Frequency & Percentage \\
\hline \multirow{3}{*}{ Surface } & Low & - & 0 & 0 \\
\hline & Medium & $\begin{array}{l}\text { S3,S9,S10,S11,S13,S14,S15,S16, } \\
\text { S17,S19 }\end{array}$ & 10 & 50 \\
\hline & High & $\mathrm{S} 1, \mathrm{~S} 2, \mathrm{~S} 4, \mathrm{~S} 5, \mathrm{~S} 6, \mathrm{~S} 7, \mathrm{~S} 8, \mathrm{~S} 12, \mathrm{~S} 18, \mathrm{~S} 20$ & 10 & 50 \\
\hline \multirow{3}{*}{$\begin{array}{l}\text { Recognizing } \\
\text { Elements }\end{array}$} & Low & - & 0 & 0 \\
\hline & Medium & $\mathrm{S} 1, \mathrm{~S} 3, \mathrm{~S} 7, \mathrm{~S} 9, \mathrm{~S} 10, \mathrm{~S} 11, \mathrm{~S} 15, \mathrm{~S} 18, \mathrm{~S} 19$ & 9 & 45 \\
\hline & High & $\begin{array}{l}\mathrm{S} 1, \mathrm{~S} 2, \mathrm{~S} 3, \mathrm{~S} 4, \mathrm{~S} 7, \mathrm{~S} 9, \mathrm{~S} 10, \mathrm{~S} 11, \mathrm{~S} 12, \mathrm{~S} 14, \\
\mathrm{~S} 15, \mathrm{~S} 17, \mathrm{~S} 18, \mathrm{~S} 19, \mathrm{~S} 20\end{array}$ & 15 & 75 \\
\hline \multirow{3}{*}{$\begin{array}{l}\text { Chaining } \\
\text { Elements }\end{array}$} & Low & S2,S9,S19,S20 & 4 & 20 \\
\hline & Medium & $\mathrm{S} 3, \mathrm{~S} 10, \mathrm{~S} 11, \mathrm{~S} 12, \mathrm{~S} 13, \mathrm{~S} 14, \mathrm{~S} 15, \mathrm{~S} 16, \mathrm{~S} 17$ & 9 & 45 \\
\hline & High & $\mathrm{S} 1, \mathrm{~S} 4, \mathrm{~S} 5, \mathrm{~S} 6, \mathrm{~S} 7, \mathrm{~S} 8, \mathrm{~S} 20$ & 7 & 35 \\
\hline \multirow{3}{*}{ Encapsulation } & Low & $\begin{array}{l}\mathrm{S} 1, \mathrm{~S} 2, \mathrm{~S} 3, \mathrm{~S} 4, \mathrm{~S} 5, \mathrm{~S} 6, \mathrm{~S} 7, \mathrm{~S} 8, \mathrm{~S} 9, \mathrm{~S} 10, \mathrm{~S} 11, \mathrm{~S} 12, \mathrm{~S} \\
13, \mathrm{~S} 14, \mathrm{~S} 15, \mathrm{~S} 16, \mathrm{~S} 17, \mathrm{~S} 18, \mathrm{~S} 19, \mathrm{~S} 20\end{array}$ & 20 & 100 \\
\hline & Medium & - & 0 & 0 \\
\hline & High & - & 0 & 0 \\
\hline
\end{tabular}


When the comprehension levels are considered for PCT-5, students present mostly high levels of comprehension for this proof. For example, in the Surface level, 50\% of the students obtain high level comprehension; and similarly for Recognition Elements it is $75 \%$. From this result it can be deduced that most students comprehend the basic concept of this proof and also identify the parts and premises of the proof. Although the Surface and Recognizing Elements levels see a high degree of comprehension increase, in both Chaining Elements and Encapsulation, the high degree of comprehension decreased very fast.

In the Chaining Elements level of PCT-5, 35\% of students achieve high level comprehension, which is the best among all the other PCTs. The reason for this result may relate to high comprehension levels observed in Basic Knowledge and Recognizing Elements levels, again where the other PCTs are not. Moreover, when this result is considered against other results obtained from the PCTs and students show high performance on the first two comprehension levels, they also present low performance for the second two; however, in reverse, it is not always true. In summary, Basic Knowledge and Recognizing Elements are necessary, but not sufficient in every case.

The other result is that students performed poor at comprehension levels when more than one knowledge area is questioned, and the comprehension performance increased for comprehension facets depending on only one area of knowledge. This conclusion matches results obtained from the level of combining the parts.

\subsection{Results of Comprehension Level Analyses}

In this section, the four levels of proof comprehension are individually investigated to identify any changes or improvements obtainable from the teaching sessions. In the analysis, the students' total grades for each question are noted, and the assessing comprehension level and percentages recorded.

\subsubsection{Analysis Results: Basic Knowledge Level}

Results for the Basic Knowledge level in which the basic terms, statements and symbols in a proof are examined and their results are presented in Graph 1.

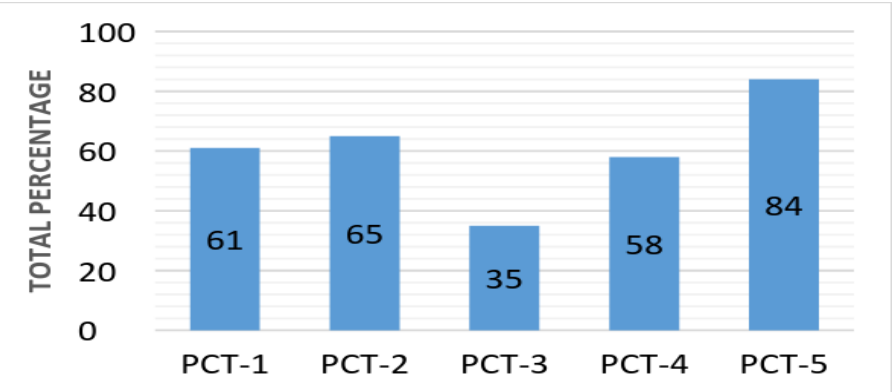

Graph 1. Comparison of Basic Knowledge level comprehension

The lowest comprehension is obtained in PCT-3 and the highest in PCT-5. Comprehension degrees do not present a general increasing or decreasing pattern. This situation relates to previous knowledge about the concepts of the theorems selected for the test. As can be seen from the students' answers, previously acquired knowledge varies even in the same proof. 


\subsubsection{Analysis Results: Recognizing Elements Level}

In this level, Logical Relationships of the transitions of proof steps are examined and students' comprehension in test grades gathered and percentages calculated and then compared. Results are shown in Graph 2.

The lowest percentages of comprehension were obtained in PCT-2 and the highest in PCT-5. After the first two PCTs, an increasing pattern is seen. In this Recognizing Elements level, which consists of explaining given proof steps, students seem to comprehend the structure of the logical relationships among the proof steps. However, it may be that these results are because asking students to interpret given proof steps is easier than asking them to construct steps from the beginning.

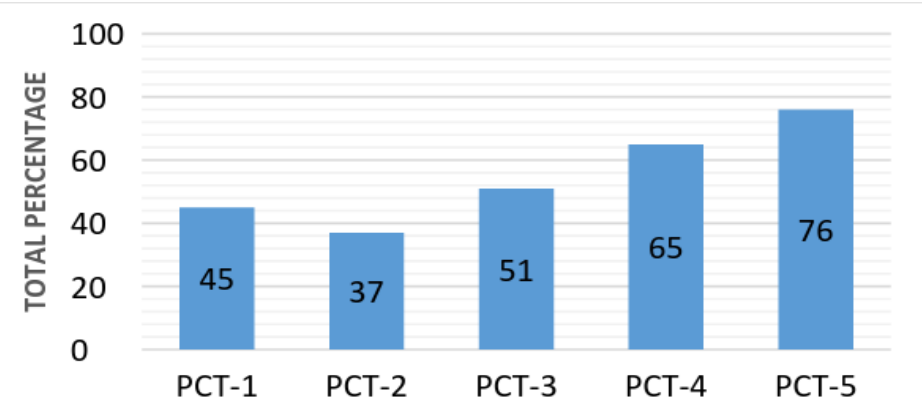

Graph 2. Comparison of Recognizing Elements level comprehension

After PCT-2, an increasing pattern is observed; concluding that recognizing elements of a proof is comprehended. Alternatively, it may be about understanding the PCT's structure, since it is a novel intervention for the students.

\subsubsection{Analysis Results: Chaining Elements}

In comparing the comprehension level of Chaining Elements, which involves combining logical arguments in a proof and defining validation, the combination of element levels for each tests' comprehension percentages are presented in Graph 3.

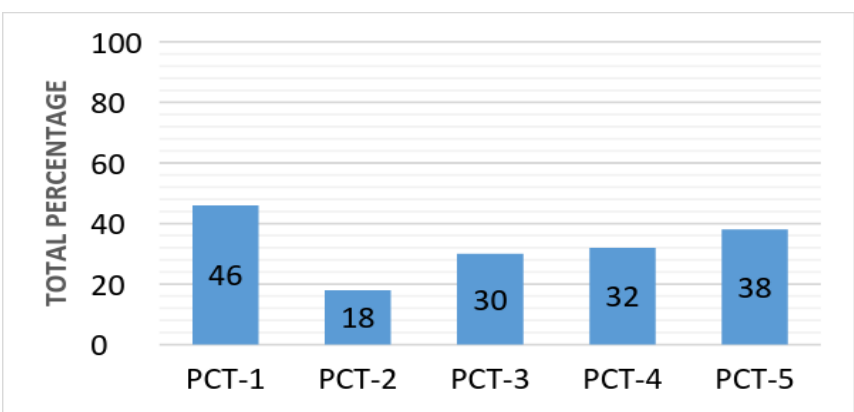

Graph 3. Comparison of Chaining Elements level comprehension

The lowest percentages of comprehension were obtained in PCT-2, and the highest in PCT-1. Generally, very low comprehension was observed in this level. The result for PCT-1 is significant as the scope of knowledge and process of theorem is known by the students. However, although students understand the transitions among proof steps, they are unable to produce the next step by themselves, struggling to determine the critical step the proof is based upon and explaining this step. They also experienced difficulties explaining what the proof is 
verifying. Except for PCT-1, although comprehension percentages are very low, they still present increasing percentages of comprehension.

\subsubsection{Analysis Results: Encapsulation Level}

Results based on percentages of comprehension at the Encapsulation level, regarding deciding how to conduct a proof in another situation and internalizing propositions of a proof, are presented in Graph 4.

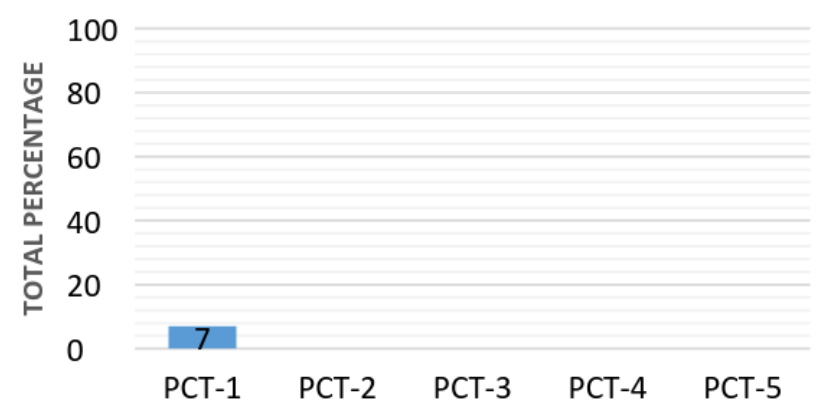

Graph 4. Comparison of Encapsulation level comprehension

Only in PCT-1 students present a degree of comprehension, although actually very low (7\%). In PCT-1, the students are given a proof about the sum of interior angles and asked to prove the sum of exterior angles. During the interview conducted with students about the given proof, it was revealed that the strategy used was not their own, but inspired from another proof related to finding the sum of exterior angles. In the other PCTs, no students performed adequate degrees of comprehension for this level.

\subsubsection{Overall evaluation of PCTs}

During analysis conducted across all PCTs, the total grades of each PCT are initially calculated. Then the percentages are calculated by considering the overall grades of the tests. The analysis results are presented in Graph 5.

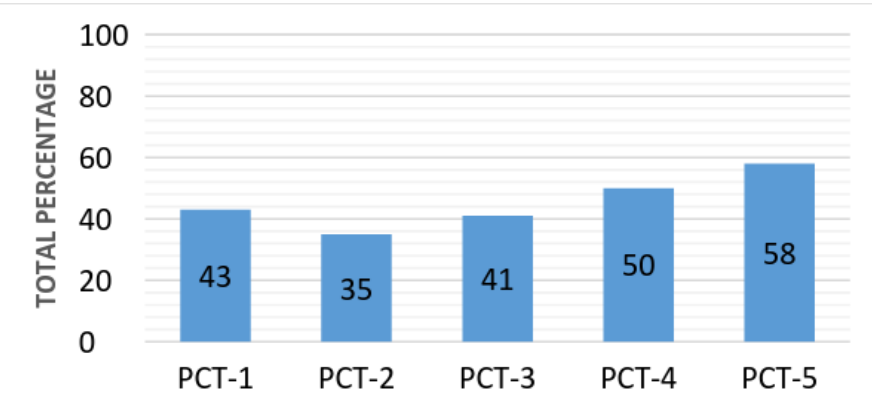

Graph 5. Overall evaluation of PCTs

The lowest comprehension level is for PCT-2 (35\%) which was conducted in the second week of the intervention process, whereas the highest is for PCT-5 (58\%) during the final week. Therefore, in general, the comprehension level tends to increase; however, this increment is nonlinear. It is suggested that this is related not only to the PCTs, but to the process of proving.

\section{DISCUSSION AND CONCLUSION}

The aim of this current study was to present 11th grade high school students' proof comprehension performance according to five prepared PCTs related with the quadrilateral unit 
of the geometry curriculum. Student performance was analyzed according to Yang and Lin's (2008) multilayered model, whereby a proof is comprehended with five facets among four levels.

The results obtained are discussed in this section within the multilayered model progressions. The model's first step is the Surface Level, where students acquire basic knowledge regarding the meaning of statements and symbols in a proof under the Basic Knowledge facet. Students mostly performed to a medium degree, except for PCT-5. Although the proof in PCT-5 is related to quadrilaterals, for the Basic Knowledge facet questions are all about areas of triangles. Since students' background knowledge about triangles may be better than for quadrilaterals, comprehension for PCT-5 was higher than all other PCTs for the Basic Knowledge facet. Half or more of the students performed high at the Surface level. Only for PCT-3 and PCT-4 did more than half of the students performed low or medium, showing that most comprehend the basic components of proofs, can identify preliminary knowledge and each element of a proof.

According to the literature, the most common proof comprehension problem is "not knowing the definition used in the proof" (Moore, 1994, p. 251) and deficiencies about mathematical definitions, roles, the importance of definition on mathematics, and how those definitions can be used while proving (Atwood, 2001; Edwards \& Ward, 2004; Knapp, 2006).

Aligned with the results of the study of Conradie and Frith (2000), in the current study students often fail to understand the meaning of key terms when reading a proof, hindering their ability to comprehend other aspects of a proof, and that less successful students may not try to understand the meaning of key terms and statements (Weber, Brophy, \& Lin, 2008).

The second level, Recognizing Elements, contains the Logical Status and Summarization facets, and is where students identify the logical status of statements used either explicitly or implicitly in a proof. Logical Status is explained as "recognizing a condition applied directly, judging the logical order of statements and recognizing which properties are applied" (Lin \& Yang, 2007, p.351). In this facet students are expected to identify premises and select logically. Students mostly performed moderately, except for PCT-2 and PCT-5 where they performed outstandingly, meaning they comprehended the sequence of given arguments in a proof. In PCT-5, students must identify critical steps by questioning equalities in the given proof and also some premises. There may be two reasons for outstanding comprehension for this facet of PCT-5. Firstly, since PCT-5 is the final test, students may better understand the structure of these proof questions; and secondly, although the context of the proof is quadrilaterals, PCT5's questions are also answerable by considering the properties of triangles, which may be better known by students. Moreover, for the Summarization facet, which is defined by Lin and Yang as "identifying critical procedures, premises or conclusions and identifying critical ideas of a proof" (2007, p.751), students presented medium performance for all PCTs, except for PCT-3 which directly asked the critical steps for the given proof. Students did not perform well since they have difficulties decontextualizing the given proof and identifying the necessary steps. In this facet, besides PCT-3, students performed moderate comprehension, but percentages were borderline to low comprehension, suggesting deficiencies with identifying critical procedures of a given proof. This result parallels "deficiencies on knowledge of context and strategies" as reported by Knapp (2006). For the Recognizing Elements level, all PCTs except for PCT-1 and PCT-2 showed high performance for 50\% of students. On this topic, Mejia-Ramos et al. (2012) stated that it needs to not only identify the logical status of statements in proofs but also recognize the logical relationship between the statement being proven the assumptions and conclusions of the proof".

The third level of the proof comprehension model is Chaining Elements, in which students comprehend the way in which different statements whose logical status are identified 
in the previous level, are connected in the proof by identifying their logical relations. This level contains two facets, Generality and Application. Generality facet was introduced by Lin and Yang (2007) as "justifying correctness and identifying what is validated by the proof" (p.751), and students performed moderately for most PCTs, except for PCT2 and PCT3. In these two PCTs, students performed very low when asked to confirm why the given proof is correct. According to Schoenfeld (1994), students mostly focusing on visualization may come away with the misconception that "seeing is believing". For the Application facet, Lin and Yang's (2007) final stage in which creation of new knowledge is sought, except for three students who confessed they had seen the proof before, no others presented a satisfactory performance. Similar to this finding, Heinze, Cheng, and Yang (2004) identified that students performed well in conducting proof if given familiar proof settings. Moreover, since students are introduced to proofs in secondary school they are more challenged in this comprehension level than the others. This finding aligns to results of a study by Hemmi (2008) who stated that having less experiences on proof (in the process of comprehending meaning of proof or learning to construct own proof) then proof is invisible for them based on the condition of transparency.

The final level for the model is Encapsulation; understanding whether students conduct interiorization of the proof as a whole. No students satisfactorily achieved this level, paralleling results of Yang and Lin (2008). In their study, Yang and Lin (2008) stated that Encapsulation, the fourth level of proof comprehension's theoretical framework, is not aimed at secondary school, claiming this comprehension level would occur in advanced mathematics education.

In general, comprehension levels tended to increase through the PCTs since the lowest comprehension occurred in PCT-2 during the second week of application, and the highest occurred in PCT-5 during the final last week. However, this increment is nonlinear. The current study's researchers suggest this is related not only to the PCTs, but also the process of proving. Since proofs require different mental procedures (Ball et al., 2002), obtaining different comprehension levels for each proof is a natural result.

\section{IMPLICATIONS}

According to the current study's results, it was observed that no students could achieve the Encapsulation level; conducting a proof in various ways or proving different theorems by using the same proof methods. Therefore, no participants reached the NCTM (2000) standards of proof and proving which are to "develop and evaluate mathematical arguments and proofs" and "select and use various types of reasoning and methods of proof" (p.342). Yang and Lin (2008) also obtained similar results and defined Encapsulation level as the "global level". In particular, they indicated that their instrument was not aimed at diagnosing if a student had reached this last level (p.71). This result led them to suggest the wording of the standards written in the mathematics curriculum. In the standards wording, students are asked to "do proof"; however, if they are written as "understand proof" or "interpret proof" it may be easier to reach the aims of teaching and learning about proof, after which, conducting a proof may be constructed on such understanding.

Another result obtained from the current study was no linear increase or decrease of comprehension level and achievement on facets. This reinforces that proof comprehension is a multilayered action and complex concept (Selden \& Selden, 1995) involving various mental processes (Ball et al., 2002; Tall, 1992), and that PCTs can be used as a tool for contributing to this complex understanding.

Among the five PCTs, the highest comprehension was obtained from the level containing knowledge about definition, properties, and the meanings of symbols. Achievement and comprehension decreased with identifying the components of a proof needing higher mathematical skills. Özer \& Arıkan (2002) obtained similar results with almost no students 
reaching the necessary level of conducting a proof among 10th graders. However, the current study saw a slight improvement among the PCTs which can be interpreted as affecting students' comprehension of proofs. In summary, although students have low level comprehension from proof comprehension tests, the PCTs positively affected their comprehension therefore PCTs could be used both for teaching proof and evaluating proof comprehension.

\section{Acknowledgements}

This study is derived from a part of master thesis of the first author.

\section{ORCID}

Bahattin İnam (D) https://orcid.org/0000-0002-6212-8013

Işıkhan Uğurel (Di) https://orcid.org/0000-0003-4067-1522

Burçak Boz Yaman (D) https://orcid.org/0000-0002-0922-3652

\section{REFERENCES}

Alcock, L., \& Wilkinson, N. (2011). e-Proofs: Design of a resource to support proof comprehension in mathematics. Educational Designer, 1(4). Retrieved from http://www.educationaldesigner.org/ed/volume1/issue4/article14/index.htm?\&popups=o ff

Almeida, D. (2003). Engendering Proof Attitudes: Can The Genesis of Mathematical Knowledge Teach Us Anything?. International Journal of Mathematical Education in Science and Technology, 34(4), 479-488.

Atwood, P.R. (2001). Learning to Construct Proofs in a First Course on Mathematical Proof (Doctoral dissertation). Retrieved from https://scholarworks.wmich.edu/cgi/viewcontent.cgi?referer=https://www.google.com/ \&httpsredir $=1 \&$ article $=2352 \&$ context $=$ dissertations

Ball, D. L., Hoyles, C., Jahnke, H. N., \& Movshovitz-Hadar, N. (2002). The Teaching of Proof. ICM, 3, 907-920.

Büyüköztürk, Ş., Kılıç-Çakmak, E., Akgün, Ö. E., Karadeniz, Ş., \& Demirel, F. (2014). Bilimsel Araştırma Yöntemleri. (16th ed.). Ankara: Pegem Akademi.

Conradie, J., \& Frith, J. (2000). Comprehension Tests in Mathematics. Educational Studies in Mathematics, 42(3), 225-235.

Creswell, J. W. (2003). Research Design: Qualitative, Quantitative, and Mixed Methods Approaches. 2nd ed. Sage, Thousand Oaks.

Di Martino, P., \& Maracci, M. (2009). The Secondary-Tertiary Transition: Beyond the Purely Cognitive. In M. Tzekaki, M. Kaldrimidou, \& H. Sakonidis (Eds.), Proceedings of 33rd Conference of the International Group for the Psychology of Mathematics Education (pp.401-408). Thessaloniki, Greece.

Duval, R. (2002). Proof understanding in mathematics: What ways for students. In F. L. Lin (Ed.), International conference on mathematics - "Understanding proving and proving to understand" (pp.61-77). Taipei: National Science Council and National Taiwan Normal University.

Edwards, B.S., \& Ward, M.B. (2004). Surprises from mathematics education research: Student (mis)use of mathematical definitions. American Mathematical Monthly, 111, 411-424

Heinze, A., Cheng, Y. H., \& Yang, K. L. (2004). Students' performance in reasoning and proof in Taiwan and Germany: Results, paradoxes and open questions. ZDM, 36(5), 162-171. doi:10.1007/BF02655668 
Hemmi, K. (2008). Students' encounter with proof: the condition of transparency. ZDM, The Special Issue on Proof, 40(3), 413-426.

Houston, S. K. (1993a). Comprehension Tests in Mathematics. Teaching Mathematics and its Applications, 12(2), 60-73.

Houston, S. K. (1993b). Comprehension Tests in Mathematics: II. Teaching Mathematics and its Applications, 12(2), 113-120.

İnam, B., \& Uğurel, I. (2016). İspat kavrama testine dayalı bir öğretim uygulamasında karşılaşılan güçlükler ve sürece müdahale yolları. Mersin Üniversitesi Eğitim Fakültesi Dergisi, 12(1), 1-21.

Knapp, J. L. (2006). Students' appropriation of proving practices in advanced calculus (Doctoral dissertation). Retrieved from ProQuest Dissertations and Theses Global. (Accession Order No. AAT 3241300)

Koshy, V. (2005). Action Research for Improving Practice. London: Paul Chapman Publishing.

Leron, U. (1983). Structuring Mathematical Proof. American Mathematical Monthly, 90(3), 174-185.

Lin, F. L., \& Yang, K. L. (2007). The Reading Comprehension of Geometric Proofs: The Contribution of Knowledge and Reasoning. International Journal of Science and Mathematics Education, 5(4), 729-754.

MEB [Milli Eğitim Bakanlığı] (2010). 11.Sınıf Geometri Öğretim Programı. Ankara: MEB. Retrieved from http://ogm.meb.gov.tr/

MEB [Milli Eğitim Bakanlığı] (2013). Ortaöğretim Matematik Dersi (9, 10, 11 ve 12. Sinıflar) Ögretim Programı. Ankara: MEB. Retrieved from http://ogm.meb.gov.tr/

Mejia-Ramos, J. P. (2008). The construction and evaluation of arguments in undergraduate mathematics: A theoretical and a longitudinal multiple-case study. (Doctoral dissertation). University of Warwick, U.K.

Mejia-Ramos, J. P., Fuller, E., Weber, K., Rhoads, K., \& Samkoff, A. (2012). An Assessment Model for Proof Comprehension in Undergraduate Mathematics. Educational Studies in Mathematics, 79(1), 3-18.

Moore, R. C. (1994) Making the Transition to Formal Proof. Educational Studies in Mathematics, 27(3), 249-266.

NCTM [National Council of Teachers of Mathematics]. (2000). NCTM Principles and Standards for School Mathematics. Reston. VA: NCTM.

Özer, Ö., \& Arıkan, A. (2002). Lise matematik derslerinde öğrencilerin ispat yapabilme düzeyleri. In Proceedings of V. National Science and Mathematics Education Congress, ODTÜ, Ankara. Retrieved from http://old.fedu.metu.edu.tr/ufbmek5/b_kitabi/PDF/Matematik/Bildiri/t245d.pdf

Remillard, K. S. (2010). Exploring the learning of mathematical proof by undergraduate mathematics majors through discourse analysis. In Proceedings of the 13th Annual Conference on Research in Undergraduate Mathematics Education. Raleigh, NC: RUME (published online). Retrieved from http://sigmaa.maa.org/rume/crume2010/Archive/Remillard.pdf

Roy, S., Alcock, L., \& Inglis, M. (2010). Supporting Proof Comprehension: A Comparative Study of Three Forms of Presentation. In Proceedings of the 13th Annual Conference on Research in Undergraduate Mathematics Education. Raleigh, NC: RUME (published online). Retrieved from http://sigmaa.maa.org/rume/crume2010/Archive/Roy\%20et\%20al.pdf 
Sarı, M. (2011). Üniversite Öğrencilerinin Matematiksel Kanıt ile İlgili Güçlükleri ve Kanıt Ögretimi. (Doctoral dissertation). Retrieved from National Thesis Center. (Accession Order No. 299545)

Schoenfeld, A. (1994). Reflections on doing and teaching Mathematics. In A. Schoenfeld (Ed.). Mathematical Thinking and Problem Solving (pp.53-69). Hillsdale, NJ: Lawrence Erlbaum Associates.

Selden, J., \& Selden, A. (1995). Unpacking the logic of mathematical statements. Educational Studies in Mathematics, 29(2), 123-151.

Stylianides, A.J. (2007). Proof and proving in school mathematics. Journal of Research in Mathematics Education, 38(3), 289-321.

Tall, D. (1992). The Transition to Advanced Mathematical Thinking: Functions, Limits, Infinity and Proof. In D. A. Grouws (Ed.), Handbook of Research on Mathematics Teaching and Learning (pp.495-511). Reston, VA: National Council of Teachers of Mathematics/Macmillan.

Uğurel, I., \& Moralı, S. (2010). Bir Ortaöğretim Matematik Dersindeki İspat Yapma Etkinliğine Yönelik Sınıf içi Tartışma Sürecine Öğrenci Söylemleri Çerçevesinde Yakından Bakış. Buca Eğitim Fakültesi Dergisi, 28, 135-154.

Weber, K., \& Mejia-Ramos, J.P. (2011). Why and how mathematicians read proofs: An exploratory study. Educational Studies in Mathematics, 76(3), 329-344.

Weber, K., Brophy, A., \& Lin, K. (2008). Learning about advanced mathematical concepts by reading text. In Proceedings of the 11th Conference on Research in Undergraduate Mathematics Education. San Diego, California: RUME (published online). Retrieved from http://sigmaa.maa.org/rume/crume2008/Proceedings/Weber\%20LONG.pdf

Yang, K. L. (2012). Structures of Cognitive and Metacognitive Reading Strategy Use for Reading Comprehension of Geometry Proof. Educational Studies in Mathematics, 80(3), 307-326.

Yang, K. L., \& Lin, F. L. (2008). A model of reading comprehension of geometry proof. Educational Studies in Mathematics, 67(1), 59-76.

Yang, K. L., Lin, F. L., \& Wang, Y.T. (2008). The effects of proof features and question probing on understanding geometry proof. Contemporary Educational Research Quarterly, 16(2), 77-100.

Yıldırım, A., \& Şimşek, H. (2013). Sosyal Bilimlerde Nitel Araştırma Yöntemleri (9th ed.). Ankara: Seçkin Yayıncılık.

Yıldız, G. (2006). Lisans Seviyesinde Genel Matematik Dersindeki Teorem ve Íspatlart Anlamaya Yönelik Kavrama Testinin Hazırlanması Uygulanması ve Öğrenci Görüşlerinin Değerlendirmesi. (Master's thesis) Retrieved from National Thesis Center. (Accession Order No. 187622)

Zazkis, R., \& Zazkis, D. (2014). Proof scripts as a lens for exploring proof comprehension. In T. Fukawa-Connolly, G. Karakok, K. Keene, \& M. Zandieh (Eds.), Proceedings of the 17th Annual Conference for Research in Undergraduate Mathematics Education (pp.1198-1204), Denver, CO. 


\section{Appendix: PCT-1}

\section{Theorem:}

Summation of interior angles of a quadrilateral is $360^{\circ}$

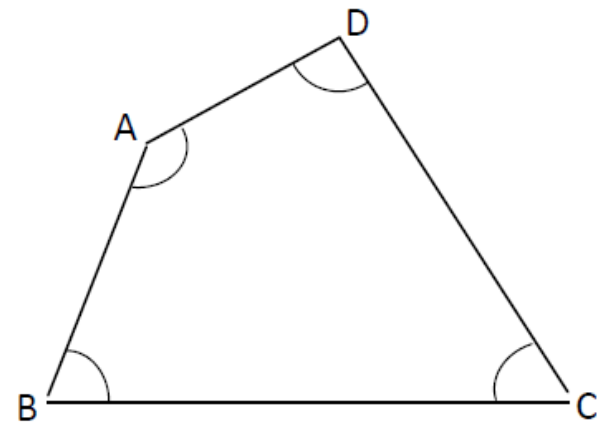

\section{Proof:}

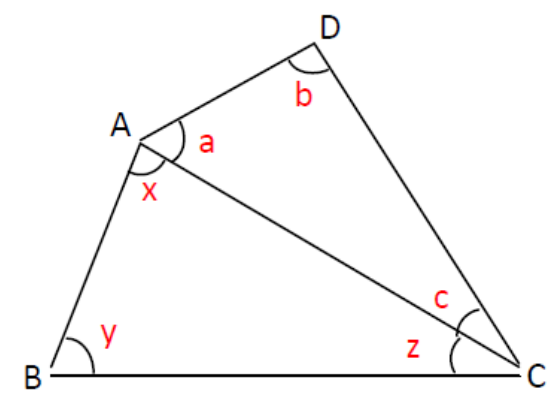

In the quadrilateral $\mathrm{ABCD}$, draw diagonal $[\mathrm{AC}]$ and construct $\mathrm{ABC}$ and $\mathrm{ACD}$ triangles.

(Step-1)

In figure $\mathrm{x}, \mathrm{y}, \mathrm{z}, \mathrm{a}, \mathrm{b}$ and $\mathrm{c}$ are representing measurement of the related angles.

(Step-2)

In $\mathrm{ABC}$ triangle $\mathrm{x}+\mathrm{y}+\mathrm{z}=180^{\circ}$

(Step-3)

In ACD triangle $\mathrm{a}+\mathrm{b}+\mathrm{c}=180^{\circ}$ dir.

(Step-4)

Use the given theorem and proof to answer the following questions.

1. Define the terms "quadrilateral", "triangle", and "diagonal" used in the proof.

2. Is the equality given in Step 3 true? Explain.

3. Explain how the equality given in Step 5 is obtained?

4. In the proof, if Step 1 and Step 2 change order, is the proof still true?

5. In Step 1, if [BD] is drawn instead of [AC], is the proof still true?

6. According to you, what are the critical step(s) for which proof is based? Explain.

7. When the whole proof is considered, do you think this proof is true? Explain.

8. State the conducted proof with your own words.

9. Can you prove this theorem in a different way?

10.Try to obtain summation of the exterior angles of a quadrilateral by considering the given theorem and proof. 